University of Wollongong

Research Online

Australian Institute for Innovative Materials -

Papers

Australian Institute for Innovative Materials

$1-1-2015$

Bio-interface of conducting polymer-based materials for neuroregeneration

Bo Weng

Southwest University, bweng@uow.edu.au

Jianglin Diao

Southwest University

Qun Xu

Zhengzhou University

Yuqing Liu

University of Wollongong, yl037@uowmail.edu.au

Changming $\mathrm{Li}$

Southwest University

See next page for additional authors

Follow this and additional works at: https://ro.uow.edu.au/aiimpapers

Part of the Engineering Commons, and the Physical Sciences and Mathematics Commons

Research Online is the open access institutional repository for the University of Wollongong. For further information contact the UOW Library: research-pubs@uow.edu.au 


\title{
Bio-interface of conducting polymer-based materials for neuroregeneration
}

\begin{abstract}
Nerve system diseases like Parkinson's disease, Huntington's disease, Alzheimer's disease, etc. seriously affect thousands of patients' lives every year, making them suffer from pains and inconvenience. Recently, bio-interfaces between neural cells/tissues and polymer based biomaterials attracted worldwide attention due to the ability of polymer based biomaterials to serve as nerve conduits, drug carriers and neurites guidance platform in neuroregeneration. The role that bio-interface played and the way it interacted with neural tissues and cells have been thoroughly investigated by the researchers. In this paper we mainly focus on reviewing the bio-interface between nerve tissues/cells and advanced functional biocompatible polymers, such as conducting polymers and advanced carbon composite materials. These advanced polymers can provide combined interfacial stimulations including interfacial external neurotrophic factors (NTFs) delivery, electrical stimulation, surface guidance and molecules decoration to lesion cells and tissues to promote neuroregeneration in vitro and in vivo, and have contributed greatly to nerve diseases therapy. At the end of this review, the criteria of polymer based biomaterials utilized in neuroregeneration are summarized and the perspectives for future development of bio-interfaces are also discussed.
\end{abstract}

\section{Keywords}

materials, polymer, neuroregeneration, conducting, bio, interface

Disciplines

Engineering | Physical Sciences and Mathematics

\section{Publication Details}

Weng, B., Diao, J., Xu, Q., Liu, Y., Li, C., Ding, A. \& Chen, J. (2015). Bio-interface of conducting polymerbased materials for neuroregeneration. Advanced Materials Interfaces, 2 (8), 1500059-1-1500059-23.

\section{Authors}

Bo Weng, Jianglin Diao, Qun Xu, Yuqing Liu, Changming Li, Ailing Ding, and Jun Chen 


\title{
WILEY-VCH
}

Article type: Review

\section{Bio-interface of Conducting Polymer-based Materials for Neuroregeneration}

Bo Weng*, Jianglin Diao, Qun $X^{c}$, Yuqing Liu, Changming Li, Ailing Ding and Jun Chen*

\author{
Dr. Bo Weng, Prof. Changming Li, Mr. Jianglin Ding and Ms. Ailing Ding \\ ${ }^{a}$ Chongqing Key Lab for Advanced Materials \& Clean Energies of Technologies \\ Institute for Clean Energy and Advanced Materials \\ Southwest University \\ 2 Tiansheng Rd, Beibei, Chongqing, China 400715. \\ E-mail: bweng1984@gmail.com \\ Asso. Prof. Jun Chen, Ms. Yuqing Liu \\ ${ }^{b}$ Intelligent Polymer Research Institute \\ ARC Centre of Excellence for Electromaterials Science \\ University of Wollongong, NSW 2522, Australia. \\ E-mail:junc@uow.edu.au \\ Prof. Qun Xu \\ ${ }^{\mathrm{c} C o l l e g e}$ of Materials Science and Engineering \\ Zhengzhou University, Zhengzhou 450052, China.
}

Keywords: Neuroregeneration; Bio-interface; Conducting Polymers; Biomaterials.

Nerve system diseases like Parkinson's disease, Huntington's disease and Alzheimer's disease etc. seriously affect thousands of patients' lives every year, making the patients suffer from pains and inconvenience brought about by these diseases. Recently, bio-interface between neural cells/tissues and polymer based biomaterials attracted worldwide attention due to the ability of polymer based biomaterials to serve as nerve conduits, drug carrier and neurites guidance platform in neuroregeneration. The role that bio-interface played and the way it interacted with neural tissues and cells have been thoroughly investigated by the researchers. In this paper we mainly focus on reviewing bio-interface between nerve tissues/cells and advanced functional biocompatible polymers, such as conducting polymers and advanced carbon composites materials.. These advanced polymers can provide combined interfacial stimulations including interfacial NTFs delivery, electrical stimulation, surface guidance and molecules decoration to lesion cells and tissues to promote neuroregeneration in vitro and in vivo, and have contributed greatly to nerve diseases therapy. At the end of this review, the criteria of polymer based biomaterials utilized in neuroregeneration are summarized and the perspectives for future development of bio-interfaces are also discussed.

\section{Introduction}




\section{WILEY-VCH}

The nerve system is a complex and sophisticated system that regulates and coordinates body activities. The nerve system is vulnerable to various external and internal influences and can be damaged by multiple reasons, such as trauma, infection, degeneration, blood flow disruption and autoimmune disorders ${ }^{[1]}$. These damages may cause serious nerve system diseases, such as spinal cord injury, Parkinson's disease (PD) ${ }^{[2]}$, Huntington's disease (HD) ${ }^{[3]}$ and Alzheimer's disease(AD) ${ }^{[4]}$ etc., which affect thousands of peoples' lives every year and bring deep sufferings to human beings.

The therapies for these diseases attracted a broad range of attention worldwide from local communities to the research industry as they are expected to relieve the patients' suffering to some extent. The nerve system diseases currently can be treated in hospital by doctors in neurology, neurological surgery and rehabilitation department via medicine, surgery and physical methods for nerve system recovery. Meanwhile, huge attention has been paid by global researchers on more effective neuroregeneration methods to enhance nerve system diseases therapy ${ }^{[5]}$.

To understand the importance of neuroregeneration, the pathogenesis of neural diseases and how neuroregeneration approaches influence neural tissues/cells should be discussed. The neural system is constituted of two major parts, the central nervous system (CNS) which consists of the spinal cord and brain, and the peripheral nervous system (PNS) which consists of all other neural elements according to their different functions ${ }^{[6]}$. Most neural system diseases are caused by damages to the CNS, including spinal cord injury (SCI) and brain damage. Spinal cord injury is a major cause of disability. The functional decline of SCI is contributed to by both direct mechanical injury and secondary pathophysiological mechanisms that are induced by the initial trauma. These mechanisms initially involve widespread haemorrhage at the site of injury and necrosis of the central nervous system (CNS) cellular components. At later stages of injury, the cord is observed to display reactive gliosis. The actions of astrocytes as well as numerous other cells in this response create an environment that is highly 


\section{WILEY-VCH}

nonpermissive to axonal regrowth. This affects the communication between the PNS and the brain and finally leads to disability ${ }^{[7]}$.

Meanwhile, damage to the brain, including neurotropic viral infections, stroke, paraneoplastic disorders, traumatic brain injury and multiple sclerosis ${ }^{[8]}$, which can trigger slow and progressive dysfunction and loss of neurons and axons in the CNS, is the primary pathological feature of acute and chronic neurodegenerative conditions such as $\mathrm{AD}, \mathrm{PD}$ and HD. For example, in Alzheimer's disease, characteristic dementia is attributed to widespread degeneration of cerebral cortical neurons and secondary cholinergic differentiation; in Parkinson's disease, the classic hypokinetic movement disorder seems to result from loss of modulatory dopaminergic input to the striatum from the substantia nigra; and in Huntington's disease, loss of striatal output neurons leads to the motor, cognitive, and affective abnormalities that are characteristic of this disease ${ }^{[9]}$.

Evidence suggests that the brain, like many other tissues, is in a state of dynamic equilibrium. It has an endogenous population of neuronblast that proliferate in response to environmental and pharmacological manipulations and that can replace cells lost in some experimental lesions ${ }^{[10]}$. The adult rodent brain generates neuronal progenitor cells in the subventricular zone (SVZ) and in the dentate gyrus of the hippocampus throughout life. The persistence of neurogenesis in the adult mammalian brain suggests that endogenous precursors are a source for neuronal replacement after brain injury. After stroke in the adult brain, the neuroblast population is greatly expanded in the SVZ, and these cells are recruited to areas bordering the infarct, where they can differentiate into neurons and thereby replace lost neurons ${ }^{[11]}$. Although the expansion of neuroblast population may help to promote the neuroregenerative process, the fact remains that neurodegenerative disorders such as $\mathrm{AD}, \mathrm{PD}$ and $\mathrm{HD}$ are characterized by continuous loss of neurons that are not replaced, which means that a primary deficit in neural stem-cell proliferation; migration, or differentiation, or both, might contribute to net cell loss and neuronal circuit disruption in these disorders. This claim, supported by 


\section{WILEY-VCH}

work with animals, proposes that failure of endogenous neural stem cells to respond appropriately and replace neurons lost to neurodegenerative disease might be a further common mechanism that contributes to functional compromise ${ }^{[12]}$. Therefore, promoting neuroregeneration via multiple approaches, such as stimulating neurogenesis, to generate regenerative neurons to replace lesion neurons and axons can be a common method for neural system diseases treatments.

Neuroregeneration, as a fast growing area dedicated to new methods to recover nerve functionality after injury in treatment, refers to the regrowth or reconstruction of nerve cells, tissues or cell products via multiple stimulation methods to nerve cells or tissues ${ }^{[10]}$. Polymers have controllable interfacial, physical and chemical properties, micro- and nanoprocessable abilities, as well as tunable conductivities to make them ideal platform materials for neuroregeneration ${ }^{[13]}$. The development of advanced biocompatible polymers afforded more possibilities in neuroregeneration by offering multiple interfacial stimulations for neuroregeneration, including providing external neurotrophic factors (NTFs) to the nerve injury site directly or by novel cyto-compatible scaffolds to stimulate cells biologically ${ }^{[14-17]}$, using nerve conduits at lesion gaps as templates to guide nerve neurites growth and stimulating cells via various cues such as topographical cues ${ }^{[18-21]}$, electrical cues ${ }^{[22]}$ and physical cues ${ }^{[23-25]}$. The realization of these stimulations is more determined by the surface properties of the polymers and the interactions between cells/tissues and polymer surfaces rather than the bulk properties of biopolymers.

Polymers can provide interfacial stimulations to nerve cells/tissues in the following ways: 1) Interfacial NTFs delivery: biodegradable polymers (poly(DL-lactide)co-glycolide (PLGA) ${ }^{[14 \text {, }}$ ${ }^{15]}$, poly(e-caprolactone) (PCL) ${ }^{[16]}$, polyL-lactic acid (PLLA $)^{[17]}$ etc.) are ideal platforms materials for interfacial delivery of NTFs to abnormal tissues in various neural disease treatments; 2) Interfacial surface guidance: processable biopolymers can be fabricated into aligned structures at different scales, including nanofibers ${ }^{[26-28]}$, microfibers ${ }^{[18,19]}$, 


\section{WILEY-VCH}

microlines $^{[20,21]}$ and micro-tunnels ${ }^{[29,30]}$, to influence interfacial interactions between neural cells/tissues and surfaces; 3) Interfacial electrical stimulation (ES): ES could be applied on the surface of nerve cells via biocompatible conducting polymers (CPs) platforms to enhance nerve cell proliferation and neurites outgrowth ${ }^{[22]}$; 4) Interfacial molecules decoration: multiple biomolecules and proteins can be decorated onto the surfaces of polymer scaffolds to improve the adhesion and growth of nerve cells ${ }^{[31]}$; 5) Combined interfacial stimulations: recent research revealed that the combinations of these stimulation methods can further improve the interfacial interactions between lesion cells/tissues and polymer based biomaterials, as well as the effects of nerve diseases treatments ${ }^{[29,32]}$.

The studies of using polymers in neuroregeneration started from traditional biopolymers, such as PLGA ${ }^{[29,33]}$, polyglycolic acid (PGA) ${ }^{[34]}$, polylactic acid (PLA) ${ }^{[35]}$ etc, due to their ability to provide interfacial NTFs delivery to lesion nerve tissue/cells and their biocompatibility. However, this simple and monotonous stimulation method cannot fulfil the developing requirements for multiple and combined stimulations in neuroregeneration. $\mathrm{CPs}$, as possible candidates to resolve this question, were investigated widely in this area as platform materials for neuroregeneration. Firstly, CPs are conductive and thus can provide interfacial ES to nerve tissue/cells seeded on them. Secondly, CPs can provide controlled interfacial NTFs delivery by incorporating NTFs as dopants in polymer chains to realize a controllable long-term interfacial NTFs delivery. In addition, other biomolecules for cell adhesion or further modification can also be incorporated into CPs as dopants. Moreover, most CPs are processable and thus can be fabricated into various structures, including microtubes, microlines, microfibers and nanofibers, to provide interfacial surface guidance to neuron tissues/cells. Therefore, CPs can be considered as the most suitable platform materials for their ability to combine multiple interfacial stimulations. 


\section{WILEY-VCH}

In this paper all kinds of stimulations that traditional polymers and CPs can provide will be reviewed and compared for their advantages and disadvantages. Bio-interface effects of traditional synthetic and natural biodegradable polymers, e.g. PLGA, PLA, chitosan, would be only briefly reviewed for their limitations discussed above. The most recent progress of the applications of functional materials (CPs, carbon nanotubes (CNTs), graphene, etc.) in neuroregeneration and their interfacial properties will be focused upon and reviewed in detail. The criteria and prospectivity of the bio-interface of polymer based biomaterials will also be discussed.

\section{Bio-interface of traditional Biopolymers in Neuroregeneration}

The earliest utilization of polymers in neuroregeneration was aroused by the increasing needs for delivering NTFs and guiding neurites growth at lesion site in nerve disease therapy. PLGA, a synthetic biodegradable polymer, which was used as a drug carrier in other disease treatments $^{[36,}{ }^{37]}$, was firstly introduced by Camarata et al. to neuroregeneration. Biodegradable PLGA microspheres were used to deliver nerve growth factor (NGF) in both in vitro and in vivo experiments to nerve cells and brain tissues ${ }^{[14]}$. NGF can be released to a lesion site over a relatively long period with the degradation of PLGA. Results demonstrated that NGF loaded PLGA microspheres showed a continuous release into both cell culture medium and rat brain over a prolonged period of time and led to neurite outgrowth. This material is processable and the release period of NTFs can vary from weeks to years by controlling the preparation conditions and the ratio of lactide and glycolide in the polymer chains ${ }^{[38]}$.

PLGA, together with polymers with similar structures (PLA, PGA), have been studied over a relatively long period and been verified as bio-safe in both in vivo and in vitro experiments, and have already been approved by the Food and Drugs Administration (FDA) for commercial use in clinical applications ${ }^{[39]}$. Most of these materials are soluble and can be formed into multi-scale morphologies, e.g. microspheres and micro-tunnels, to provide 


\section{WILEY-VCH}

interfacial support to neural cells/tissues while providing NTFs. Also, natural biodegradable polymers including chitosan and alginate can perform similar functions and work independently or together with synthetic polymers as drug delivery platforms or nerve conduits.

Although the advantages of these traditional biopolymers are quite apparent, disadvantages of these synthetic polymers cannot be neglected either. The first disadvantage of synthetic biodegradable polymers is that the incorporation efficiency of proteins is low because of the degradation of NTFs due to the harsh synthetic conditions. In addition, PLGA and most other synthetic biodegradable polymers, such as PLLA, PCL, poly (hydroxybu- tyrate) (PHB) ${ }^{[40]}$ etc., are hydrophobic, which limits their use in tissue engineering due to their poor cell adhesion abilities.

To overcome these harsh synthetic conditions and cell adhesion issues, some water soluble and hydrophilic natural biodegradable polymers, such as chitosan ${ }^{[29,41]}$, collagen and alginate etc. ${ }^{[35]}$, were introduced into neuroregeneration to provide a similar interfacial NTFs delivery service as PLGA. In comparison with synthetic polymers like PLGA, these polymers can be prepared under more gentle conditions from aqueous solutions, which are extraordinarily beneficial to keep the bioactivities of NTFs proteins. However, the interfacial NTFs delivery provided by natural biopolymers (Chitosan, Collagen) is not as controllable as synthetic polymers (PLGA, PLLA, PLA). When used in NTFs delivery, there often occurred a burst release in the initial several hours during the release period, thus it is hard to maintain a long period sustainable protein release.

Therefore, a series of composites and structures were designed to combine the advantages of both types of biopolymers with enhanced interfacial properties, cell adhesion ability and NTFs delivery ability to promote neurites' surface interaction with NCs for clinical translation ${ }^{[35,42]}$. Hyaluronic acid (HA) is a natural biopolymer which showed distinct advantages for neural repair by preventing glial scar formation, inducing endogenous neurons migration in 


\section{WILEY-VCH}

the gel ${ }^{[30]}$. To introduce interfacial NTFs delivery ability into a HA scaffold, PLGA microspheres loaded with brain-derived neurotrophic factors (BDNF) and vascular endothelial growth factors (VEGF) were incorporated into the HA scaffold to mimic the in vivo environment in nerve repair ${ }^{[29]}$. Experimental results showed that the hydrogel composite containing BDNF and VEGF shows a significant effect on neural stem cells (NSCs) proliferation in comparison with particle-free HA scaffold (Figure 1).

Besides composite materials, special structures were also designed to promote interfacial neurites guidance together with NTFs delivery. The most often used structure in neuroregeneration made from traditional biopolymers were nerve conduits (NCs). NCs are tubular structures that are used to bridge the gap of a severed nerve, by acting as a guide for the regenerating neurites and as a barrier against the ingrowth of scar-forming tissue (Figure 2). Polymer NCs have been made of various materials of biologic (vein, alginate and chitosan) or synthetic origin (PLGA, PLA, silicone and poly(hydroxbutyrate)), as reviewed in several publications ${ }^{[43-46]}$. Depending on the material, NCs can be commonly produced by melt extrusion, dip coating, casting, or depositing material on a rotating mandrel. Typical NC dimensions for experimental use in small animals are inner diameters of 1-2 mm and lengths of several millimetres, depending on the experimental gap length ${ }^{[47]}$. The most often studied polymer NCs have been reviewed in a paper published by Pfister etc. ${ }^{[44]}$ (Table 1).

Madduri etc. fabricated thermal cross-linked collagen NCs by using spinning mandrel technology loaded with glial cell line-derived neurotrophic factor (GDNF) and NGF (Figure 2). NCs were coated with several layers of PLGA after fabrication. The release of the neurotrophic factors was sustained for over 30 days and remained biologically active, as confirmed by an in vitro bioassay using chicken embryonic dorsal root ganglion (DRG) explants ${ }^{[53]}$.This method protected the bioactivity of NTFs by trapping NTF proteins in collagen and preventing fast release of NTFs by coating a PLGA layer outside. 


\section{WILEY-VCH}

PLGA NCs filled with collagen sponge successfully provided adequate scaffolding for nerve tissue extension to serve as a connective guide across a $15 \mathrm{~mm}$ gap in the left peroneal nerve (Figure 3). In comparison with autografting, this composite nerve conduit enabled superior functional recovery and shortened recovery period ${ }^{[54]}$.

In summary, the employment of traditional polymers, including synthetic polymers (PLGA, PLLA, PLA) and natural biopolymers (chitosan, collagen, HA), successfully achieved the target of providing effective interfacial NTFs delivery to severed nerves in neuroregeneration. In addition, special NCs structures made from these polymers can also provide interfacial guidance at lesion gaps for nerve functional recovery. However, traditional polymers cannot provide interfacial ES to nerve tissues/cells due to their being insulators. Another limitation of traditional polymers is that NTFs contained in these polymers were passively released with time. The release period may be adjusted by the structure of the polymer, but a more accurate "release on demand" system cannot be created based on these polymers. The relatively simple and monotonous chemical structures made further surface modification very difficult too. More complicated systems that can provide combined interfacial stimulations were strongly needed to enhance neuroregeneration efficiency.

\section{Bio-interface of CPs in Neuroregeneration}

An electrophysiology study in the late nineteenth century suggested that neurons in the nerve system transferred information through bioelectrical signals ${ }^{[55]}$. Since then, the influence of external ES on the nerve system has been investigated in a series of studies ${ }^{[56]}$ in the midtwentieth century and it has been proven that electrical charges play an important role in stimulating either the proliferation or differentiation of various cell types ${ }^{[57]}$. Also extensive research both in vitro and in vivo has shown that electromagnetic fields play an important role in neurite extension and regeneration of transected nerve ends ${ }^{[58]}$.

These findings led researchers to think about introducing conductive platform materials to neuroregeneration in order to provide interfacial ES directly to nerve tissues/cells instead of 


\section{WILEY-VCH}

external stimulation in cell/tissue culture medium ${ }^{[58]}$. In addition, a conductive scaffold is more suitable for implantation to provide ES in vivo from a clinical perspective.

These conductive platform materials could be semi-conductors such as silicon, metals and CPs. In comparison with other conductive or semi-conductive platforms (metal, silicon), CPs showed their specific advantages in neuroregeneration. CPs were softer and more stretchable than metal or silicon ${ }^{[59]}$, which can not only promote cell adhesion on their surfaces, but can also be beneficial for the implantation device. Also, CPs demonstrated low impedence and recorded better signals compared to metal, and thus were often used as the modification layer in nerve probe applications ${ }^{[60]}$. In addition, their semi-conductive property helped CPs platforms to avoid exorbitant current stimulation that may kill nerve tissues/cells ${ }^{[58]}$. The needs in neuroregeneration for conductive platforms and the merits that CPs had over other candidates made CPs to be chosen by researchers for investigations as platform materials in neuroregeneration.

\subsection{CPs}

Until about 30 years ago, all carbon based polymers were rigidly regarded as insulators. In 1977, it was found that polyacetylene could be rendered conductive by doping ${ }^{[61]}$. Since then, a series of conductive polymers, including polyaniline (PANi), polypyrrole (PPy) and polythiophenes such as poly(3,4-ethylenedioxythiophene) (PEDOT) (Figure 4), have been widely investigated and applied in various areas including neuroregeneration.

CPs are organic polymers that can conduct electricity due to the $\pi-\pi$ coupling structure in the polymer chains. Charges can transfer through these specific conjugated structures and showed comparable conductivity to semiconductors. The interfacial, physical, chemical, and electrochemical properties (conductivity and impedance) of CPs can be fine-tuned by synthesizing polymers under different polymerization conditions. In addition, CPs also exhibited electrochemical activity and redox properties when doped with various ions. Furthermore, most CPs are soluble and processable, and thus can be fabricated into different 


\section{WILEY-VCH}

topographies and patterns with enhanced interfacial properties to serve as tissue engineering scaffolds.

\subsection{Compatibility of CPs}

Biocompatibility is the key issue which determines whether a material can serve in tissue engineering or not. The in vitro and in vivo compatibility of CPs has already been proven by researchers in a series of experiments. For example, a study on PPy in nerve tissue engineering utilizes electrochemically synthesized PPy films to evaluate the biocompatibility of materials ${ }^{[62]}$. Experimental results demonstrated that PPy can support the adhesion and growth of L929 mouse fibroblast and neuro2a neuroblastoma cells in vitro. In an in vivo experiment, there was only a minimal tissue response after PPy was implanted into a rat model for 4 weeks. Studies also demonstrated that PPy is compatible with nerve cell and tissue when applying ES, ${ }^{[22,62]}$ although some evidence of toxicity was reported after long term large current stimulation (e.g. $1 \mathrm{~mA}, 96 \mathrm{~h}^{[62]}$ ). Also, some evidences showed PANi is compatible in vitro to several cell lines including PC 12 and H9c2 cardiac myoblasts ${ }^{[63]}$ and in vivo after implantation ${ }^{[64]}$.

\subsection{Interfacial ES of CPs in Neuroregeneration}

After being verified as biocompatible, PPy was firstly reported by the C.E Schimidt group in an application as a neuroregeneration scaffold in $1997^{[22]}$. In Schimidt's study, PPy film was electrochemically coated on ITO glass and used as substrates for PC 12 cell culture. PC 12 cells attached and extended well on PPy films in comparison with PLA and PLGA. The conductivity of the film was detected to be $\sim 10 \mathrm{~S} / \mathrm{cm}$. A $100 \mathrm{mV}$ potential was applied to PPy films for nerve cell stimulation in vitro to study the influence of ES on neurite extension. Results showed that PC 12 cells cultured on PPy films and subjected to ES through the film underwent a significant increase in neurite lengths compared to the ones that were not subjected to ES through the film (Figure 5). The median neurite length for PC 12 cells grown 


\section{WILEY-VCH}

on PPy and subjected to an electrical stimulus was $18.14 \mu \mathrm{m}(\mathrm{n}=5643)$ compared with 9.5 $\mu \mathrm{m}(\mathrm{n}=4440)$ for controls.

Since then, a series of approaches have been developed to enhance nerve regeneration efficiency of CPs by combining electrical, biological and topographical stimulations together in one scaffold to promote the interaction between scaffold and neural cells/tissues.

\subsection{Interfacial molecules decoration of CPs in Neuroregeneration}

To improve the surface interaction between CPs and nerve tissues/cells and enhance neuroregeneration efficiency, a series of biomolecules were decorated on CPs' polymer chains to tune the physical, chemical and interfacial properties of CPs. For example, the incorporation of NTFs can promote neurons proliferations and axons extension while the modification of other proteins (collagen, laminin etc.) can help to improve cell adhesion properties. Furthermore, some other dopant molecules, such as CS, HA, heparin dextran sulphate, can adjust hardness, roughness, modulus of CPs for further implantation in vivo. In addition, the combined utilization of these biomolecules in CPs became a trend in most recent research work.

\subsubsection{Incorporation of NTFs into CPs}

\subsubsection{Entrapment of NTFs in CPs via Electrical Deposition}

The most typical method of incorporating NTFs in CPs is the entrapment method. NTFs and monomers were mixed together in solution with supporting dopants and then followed by electrochemical deposition on a conductive substrate. NTFs were trapped in CPs film during this procedure. When ES was applied, a redox reaction occurred on the CPs films which led to the release of NTFs with dopants into the environment.

The G. G. Wallace group firstly studied the possibility of incorporation of neurotrophin-3 (NT-3) into PPy film using an electrical deposition method in 2006. The loading capacity and amount of NT-3 released from the polymer was determined using ${ }^{125}$ I-labelled NT-3 under various electrochemical conditions. Electrochemical stimulation of PPy by pulsed voltage, 


\section{WILEY-VCH}

pulsed current and CV all promoted the release rate of NT-3 compared to passive release of NT-3 unstimulated. NT-3 was released from PPy as an initial burst in the first $24 \mathrm{~h}$ followed by prolonged release over 6 days. The amount of NT-3 incorporated into the polymer was determined by the film thickness and polymerization time, with longer growth periods incorporating more NT-3 ${ }^{[65]}$.

This method has been employed in a number of studies in nerve tissue engineering applications to be proven as an effective method to deliver NTFs to nerve cells. Richardson et al. used this kind of electrodeposited PPy/tosylate(pTS)/NT-3 platform in Cochlear implants (pTS as supporting dopant), and showed that neurites outgrowth from auditory neurons (spiral ganglion neurons (SGNs)) grown on this platform is longer than that cultured on a PPy/pTS platform, which was equivalent to tissue culture plastic (passive control). ES of PPy/pTS/NT3 with a biphasic current pulse, as used in Cochlear implants, significantly improved neurite outgrowth from explants. That means this scaffold can provide a biocompatible, lowimpedance substrate for storage and release of NT-3 to help to protect auditory neurons if applied to the Cochlear implant, and will enhance neurite outgrowth ${ }^{[66]}$. A similar work using BDNF instead of NT-3 with the same protocol achieved a similar conclusion as above ${ }^{[67]}$. This PPy/pTS/NT-3 system has also been coated on platinum Cochlear implant electrodes for in vivo study. When implanted into deafened cochleae, stimulated PPy/pTS/NT-3 coated electrodes promoted a slight improvement to neural density, without affecting fibrous tissue formation ${ }^{[68]}$.

Thompson et al. then further investigated the effect of dual neurotrophins using BDNF and NT-3 on this platform. Neurite outgrowth from Cochlear neural explants grown on polymers containing both NT-3 and BDNF showed significant improvement over PPy doped only with NT-3 or BDNF, due to the synergistic effect of both neurotrophins. Neurite outgrowth was further improved when ES was applied on dual neurotrophins incorporated scaffold (Figure 6) ${ }^{[69]}$. 


\section{WILEY-VCH}

The following study by Thompson et al. showed that dopant anions were of great importance to the electrical deposited PPy/dopant/NTFs platform in their influence on the properties of PPy film and release kinetics. Different dopants, sodium salts of pTS, dodecyl benzenesulfonate (DBS), poly(styrenesulfonate) (PSS), HA and chondroitin sulfate (CS) and the ammonium salt of PMAS, were used in the synthesis of PPy with NT-3 to investigate this influence, and the results illustrated that the physical properties (roughness, conductivity) of PPy films and kinetics of NT-3 release were both affected by dopants. That is possibly due to the difference in surface area or electrochemical properties of PPy films which were caused by the size and properties of different dopant molecules. Surprisingly, PPy films doped with the smallest dopants (pTS and DBS) were found to have the best conductivity and biocompatibility with the neural tissue cultured, and demonstrated the best release kinetics as well as neurite outgrowth performance. Instead, natural biomolecule dopants, such as HA and CS, did not show any advantage in biocompatibility as assumed ${ }^{[70]}$.

Kim et al. (D. Martin group) used this method to synthesize PPy/NGF and PEDOT/NGF films for a PC 12 cells study. Optical and fluorescence microscopy revealed that PC 12 (rat pheochromacytoma) cells can well adhere to and have extended neurites on both NGFmodified substrates, indicating that the NGF in the polymer film is biologically active. In addition, electrochemical properties study revealed that the NGF-modified CPs substrates both showed very low minimum impedance ${ }^{[71]}$.

The entrapment of NTFs in CPs via electrical deposition achieved successful interfacial NTFs delivery with little passive release and created visible improvement on nerve cell proliferation and neurites extension. But it needs a high concentration of NTFs during electrochemical deposition to ensure that there were enough NTFs trapped in CPs films. The progressively passive release of NTFs into the medium may decrease the bioactivity of NTFs. Tissues/cells cannot survive long without additional NTFs supply.

\subsubsection{Chemical NTFs Modification on CPs Surface}




\section{WILEY-VCH}

To avoid the passive release of NTFs and the lost of bioactivity of NTFs, another strategy to chemically modify the NTFs on CPs surface via chemical reactions was developed. Through NTFs incorporation, it was expected that NTFs can be delivered exactly to the injury sites, and nerve cell neurite outgrowth and network formation can be enhanced without any external NTFs addition via this method ${ }^{[65]}$.

Chemical modification of NTFs on CPs scaffold surfaces can be carried out with either selected dopants that copolymerize with CPs or modified CPs monomers, even via some specific intermediate molecule. NTFs anchored on CPs through chemical modification were connected covalently to the scaffold surface and were hardly released from the CPs scaffold without ES. NTFs chemically modified on CPs can remain bioactive over a relatively long period, thus it avoids NTFs wastage during both the modification procedure and cell culture experiments.

Biotin, which is also known as vitamin $\mathrm{B}_{7}$ or coenzyme $\mathrm{R}$, is a popular intermediate molecule used in controlled drug release. Langer et al. used Biotin as dopant in PPy electropolymerization, and then incubated Biotin-doped PPy films with streptavidin to form a surface capable of attaching any biotin labeled compound. The stability of biotin-doped PPy was tested by storing the sample in PBS for 14 days. Results showed that there was no release of biotin without activation. Modified biotinylated NGF can bind to the streptavidin and be released via ES together with biotin. The stimulated released NGF remained active and caused PC 12 neurite outgrowth with no statistical difference when compared to unreleased NGF anchored on biotin-doped PPy film and unmodified NGF directly added to cell culture medium $^{[72]}$.

C. E. Schmidt group immobilized NGF on the surface of PPy film surface using an intermediate linker provided by a layer of polyallylamine conjugated to an arylazido functional group ${ }^{[73]}$. NGF was fixed to the substrate upon exposure to UV light and activation of the azido groups (Figure 7). The immobilization of $0.98 \mathrm{ng} / \mathrm{mm}^{2}$ NGF on PPy surface 


\section{WILEY-VCH}

produced similar neurite extension in PC12 cells compared to soluble NGF $50 \mathrm{ng} / \mathrm{mL}$. In addition, ES using PPy NGF further increased neurite length by $50 \%$ with respect to controls without stimulation. Cell adhesion was also improved as a consequence of the immobilization procedure. This suggested a possible method to enhance both electrical and biological stimulation to nerve cells. The only disadvantage of this method is the decrease in conductivity of PPy $\left(10^{-3}-10^{-6} \mathrm{~S} / \mathrm{cm}\right)$ in comparison with original PPy $(10 \mathrm{~S} / \mathrm{cm})$ which may affect the stability of the PPy NGF film for long term ES.

To overcome this disadvantage, the Schmidt group developed copolymers of N-hydroxyl succinimidyl ester pyrrole (PPy/NSE) and regular pyrrole, which can be immobilized with NGF without significantly hindering conductivity (Figure 8). A copolymer containing 50:50 monomer ratio of pyrrole/pyrrole-NSE was electrochemically deposited and selected for further NGF modification for its good conductivity $(\sim 8 \mathrm{~S} / \mathrm{cm})$ and active ester groups for NGF immobilization. The active ester groups were stable for up to 5 days. Application of an external electrical potential to NGF immobilized PPy films did not cause a significant release of NGF nor reduce their neurotrophic activity ${ }^{[74]}$.

Chemically modified NTFs on a CPs surface showed better controllable ability (less passive release, NTFs not consumed) with regards to entrapped NTFs by electrical deposition. However, the chemical modification procedure is more complex and normally needs more than one step to achieve final products. It is time and efforts consuming. Furthermore, chemical modification also needs specific/non-general chemical reactions on both CPs and NTFs, even the monomer had to be specifically designed, which is not suitable for clinical usage that needs massive amounts of commercial products.

\subsubsection{Incorporation of Cell Adhesion Proteins in CPs}

Physical adsorption of cell adhesion biomolecules is the most often used method in CPs tissue engineering work and is performed by dipping the CPs scaffold in cell adhesion biomolecules solution for a period of time. The cell adhesion biomolecules used in these works include 


\section{WILEY-VCH}

laminin, collagen, Poly(lysine) etc. Admittedly, this method is easy and has been widely employed in bionic labs. However, the thickness of the coating and the amount of cell adhesion biomolecules is hard to control and thus may affect the surface interaction between the nerve cells and CPs.

Similar to NTFs, modification of cell adhesion cues can be also achieved by electrical deposition entrapment. However, some evidence showed that entrapment of cell adhesion laminin peptide together with NGF in PEDOT film decreased the mechanical, electrochemical and biological performance of CPs films, although the cell adhesion property was improved $^{[23]}$.

Chemical modification of cell adhesion biomolecules can be achieved by directly binding intermediate peptide on CPs surface or by general chemical reactions with specifically chosen dopants. A modification of cell adhesion promoting peptide (GRGDS) on the CPs surface was made by firstly binding T59, a unique peptide sequence, directly to chloride-doped PPy (PPyCl) as a bio-functional linker for covalent binding of RGD. The RGD-modified PPyCl was proved to significantly promote PC12 cell adhesion, while no cell adhesion was seen on unmodified $\mathrm{PPyCl}^{[24]}$. This method can be applied to immobilize a variety of biomolecules.

Cell adhesion biomolecules can also be attached on the active functional groups of dopant molecule employed in CPs. A study utilized polyglutamic acid as the dopant for further modification of the cell adhesion cues polylysine and laminin on PPy surface via standard amide coupling reactions. Cell adhesion and neurite extension were found to occur in the micro-patterned area where positive guidance cues were attached (Figure 9) ${ }^{[25]}$.

Wallace's group recently reported a method using chondroitin sulfate (CS), an extracellular matrix molecule bearing carboxylic acid moieties, as dopant in electrochemical deposition of PPy. Type I collagen could be bound on carboxylic acid groups covalently and form a fibrillar collagen matrix (Figure 10). More PC 12 cells were adhered on PPy substrate due to this surface modification and neurite outgrowth was also demonstrated, while ES further enhanced 


\section{WILEY-VCH}

the ability for nerve regeneration ${ }^{[75,76]}$. In this work, the cell adhesion biomolecule did not serve as dopant, thus would not decrease the physical and chemical properties of CPs.

\subsubsection{Incorporation of Other Dopants and Composites}

The influence of CPs' properties on nerve cell response was studied using various dopants and composites to tune the properties and biocompatibility of CPs. The studies on CPs dopants covered a wide range of dopant molecules from small molecule (chloride $(\mathrm{Cl})$, pTS, and nitrite $\left(\mathrm{NO}_{3}\right)$ ), polymer dopants (PSS, PMAS), to biomolecule dopants (CS, HA, heparin dextran sulfate $(\mathrm{DS}))^{[31,70,77]}$. The size and properties of dopants determined the physical, chemical and interfacial properties of CPs (roughness, modulus, conductivity etc.), which strongly influenced nerve cell activities. Some biomolecules did not show obvious advantage in cellular compatibility, which is attributed to the poor CPs substrates it formed. Thus both biological activity of the dopant and its influence on CPs properties need to be considered when choosing a CPs scaffold. The aims to synthesize these CPs composites can be classified into the following categories: increasing biocompatibility, introducing biodegradability, and introducing elasticity into the CPs scaffold ${ }^{[78]}$.

Generally, natural biomolecules (HA, chitosan) would be selected as dopants when improving the biocompatibility of CPs is necessary. A PPy/HA composite was fabricated by electrical deposition of PPy/HA membrane on PPy/PSS substrate. This method retained most of the conductivity and electrochemical stability of the scaffold while successfully produced a smooth conductive, HA-containing PPy scaffold. These films retained HA on the surface for several days in vitro and promoted vascularisation in vivo ${ }^{[79]}$.

Meng et al. chemically synthesized PPy/heparin (PPy/HE) nanoparticles through emulsion polymerization at different PPy/heparin ratios and added the particles into PLLA chloroform solution under stirring to generate PPy/PLLA biodegradable membranes of $10^{2}$ to $10^{3} \Omega /$ square. The existence of HE was verified on the membrane. The conductive membranes 


\section{WILEY-VCH}

containing HE-doped PPy particles recorded significantly increased electrical stability, cell adhesion, and growth ${ }^{[80]}$.

Similar work has been done using chitosan to replace PLLA. 2.5\% PPy and 97.5\% chitosan were mixed to form a biodegradable film for Schwann cells ES. The results showed that the PPy/chitosan membranes supported cell adhesion, spreading, and proliferation with or without ES. ES applied through the PPy/chitosan composite dramatically enhanced the expression and secretion of NGF and BDNF when compared with control cells without ES ${ }^{[81]}$.

When biodegradable CPs were needed for in vitro and in vivo applications, copolymerization of PPy and degradable block poly(E-caprolactone) (PCL) and poly(ethyl cyanoacrylate) (PECA) could create biodegradable PPy/PCL and PPy/PECA. The PPy portions of the copolymers permit ES whereas the PCL or PECA blocks enable degradation by hydrolysis. The studies indicated that these new conductive degradable biomaterials have good biocompatibility and support proliferation and growth of PC12 cells in vitro (with and without ES) and neurons in vivo (without ES) ${ }^{[82]}$. However, the conductivities of the scaffold was harmed by the copolymerization of degradable blocks.

The improvements of biodegradable CPs scaffold were achieved by coating PPy onto biodegradable polymer scaffolds. Various polymers, including PLGA ${ }^{[83]}$, polycaprolactonefumarate $(\mathrm{PCLF})^{[84]}, \quad$ oligo(polyethylene glycol)fumarate(OPF) ${ }^{[85]}$ and $\operatorname{poly}(\mathrm{D}, \mathrm{L}-\mathrm{lactide}-\mathrm{co}-\mathrm{epsilon-caprolactone})(\mathrm{PDLLA} / \mathrm{CL})^{[86]}$ etc., have been employed as degradable scaffold materials. The coating of PPy showed better cell adhesion ability and can provide ES to nerve cells and tissues cultured on CPs hybrid scaffolds. Biodegradable scaffolds obtained from this way got much higher conductivities but low long-term stability due to the poor adhesion between platform polymers and CPs during degradation process.

This concern was solved by chemical polymerization of monomer with different concentrations in a biodegradable polymer solution, followed by precipitation. The surface resistivity of the PPy/PDLLA membrane with $3 \%$ PPy was as high as $1 \times 10^{3} \Omega /$ square. The 


\section{WILEY-VCH}

electrical stability was significantly better in the PPy/PDLLA composite than in the PPy coated polyester fabrics and sustained a biologically meaningful electrical conductivity in a typical cell culture environment for $1000 \mathrm{~h}^{[87]}$. This composite was fabricated into NCs for further neuroregeneration studies. When PC12 cells are seeded on these NCs and stimulated with $100 \mathrm{mV}$ for $2 \mathrm{~h}$, there is a marked increase in both the percentage of neurite-bearing cells and the median neurite length. More importantly, when this PPy/PDLLA conduit was used to repair a rat sciatic nerve defect it performed similarly to the gold standard autologous graft. These promising results illustrate the potential that this PPy/PDLLA conducting composite conduit has for neural tissue engineering ${ }^{[88]}$.

The introduction of elasticity into CPs was mainly realized using silicone. The electrical properties of the elastomeric conductors were strongly dependent on their composition, and mixtures were identified that provided high and stable conductivity. In vivo and in vitro studies for nerve repair demonstrated the feasibility of the use of conductive elastomers for peripheral nerve stimulating electrodes ${ }^{[89]}$.

By incorporating different kinds of bioactive molecules, the interfacial "release on demand" delivery of NTFs can be achieved and the properties of CPs can be tuned by carefully choosing various functional bioactive molecules as dopants, For example, CPs will have better cell adhesion ability with collagen and laminin, better biocompatibility with HA, HE and chitosan, better degradability with PCL and PECA, and become stretchable with silicone. One of the concerns of decoration of biomolucules on CPs is that most of these decorations affected the conductivity of CPs. These biomolecules dopants did not have $\pi-\pi$ coupling structures and thus harmed the conductivity of CPs. Also, other isolative additives as biodegradable polymers and silicone affected the interaction between the CPs polymer chains as well as conductivity. The balance between conductivity and other properties must be stringently kept to realize the best neuroregeneration effect. Also, new methods like modifying dopants instead of CPs to avoid conductivity loss should be developed for better 


\section{WILEY-VCH}

results. In addition, the dopants of CPs were limited to anions as the polymer chains were positively charged. Cations and neutral molecules cannot be doped on CPs polymer chains directly. More specific design and steps were needed which were not good for clinical applications.

\subsection{Interfacial surface guidance of CPs in Neuroregeneration}

In general, the strategies for neuroregeneration should address the regrowth of injury neurites, the plastic remodelling of neuronal circuitry and/or the regeneration of new nerve cells ${ }^{[90]}$. Therefore, successful scaffold platforms designs should fulfil all needs these three objects required. For example, axons regrowth requires overcoming an unfavourable and inhibitory environment, and requires proper axonal spatial organization, target recognition and the reconstruction of functional synapses. And these requirements can be partially addressed by designing proper scaffold platform with micro- and nano- structures.

To investigate the influence of the structures and scales of micro- and nanostructured CPs, various surface topographies including nanofibres, microfibres, nanotubes, micro patterns, microlines and 3-D structures were fabricated and served as platform scaffold in neuroregeneration. Techniques that were utilized for CPs scaffold fabrication include electrospinning, wet spinning, inkjet printing, extrusion printing, electron beam and template polymerization. Scales of these scaffolds ranged from $100 \mathrm{~nm}$ to nearly $1 \mathrm{~mm}$ and influenced nerve cell performance at various scales. Nerve neurite can grow along both aligned nanofibres and wet spun microfibres assisted with ES.

\subsubsection{CPs Nanofibres scaffolds}

The use of nanostructured scaffolds in neuroregeneration is primarily due to their abilities to promote neuronal adhesion, to recreate an extracellular matrix(ECM) like microenvironment and to interact with neuronal membranes at the nanoscale ${ }^{[91]}$. Although it looks like mico- and nano- structured scaffolds can both impact on tissue/cell surface guidance, such as neurites outgrowth, orientation and cell immigrations, likely by the bio-mimicry of ECM, the 


\section{WILEY-VCH}

mechanism of the interaction of nerve tissues/cells with supporting scaffolds can only occur at nanoscale level. Firstly, the secretion of neural cell adhesion molecules(NCAM, N-cadherin and integrins ${ }^{[92]}$ ) is sensitive to nanotopography as the adhesion sites on cell membranes are mainly in the 5-200 nm range. Furthermore, nerve tissues/cells demonstrated a remarkable preference for the rough surfaces which match the size of themselves (nanofibers, nanotubes etc.) in neuronal processes including proliferation, neurites growth and orientation ${ }^{[93]}$. Therefore, nanostructured scaffolds were widely investigated to provide interfacial surface guidance to nerve tissues/cells.

Electrospinning is the most common used method to generate CPs nanofibres utilized for nerve tissue engineering platforms to mimic the structural and biological function of native extracellular matrix as much as possible ${ }^{[26-28]}$. CPs nanofibres can be obtained by electrospinning CPs blended solutions with other polymers such as gelatine, collagen, poly-Llactide (PLLA) ${ }^{[26,94]}$ or by chemically coating a CPs layer onto pre-electrospun biopolymer nanofibres $^{[83,28]}$.

CPs solutions or dispersions cannot be directly fabricated into nanofibers by electrospinning due to the concentration and viscosity restrictions. Additional isolative polymers will be added to tune the rheology of CPs. Molamma P. Prabhakaran et al. has mixed doped PANi with poly ( $\varepsilon$-caprolactone)/gelatin (PG) (70:30) solution for electrospinning to obtain PANi/PG nanofibres with diameters of $112 \pm 8 \mathrm{~nm}$. Nerve stem cell culture was performed on this scaffold and ES through conductive nanofibrous PANI/PG scaffolds showed enhanced cell proliferation and neurite outgrowth compared to the PANI/PG scaffolds that were not subjected to ES ${ }^{[94]}$. The following work from this group showed that PANI/PLLA electrospun nanofibres demonstrated a quite similar performance to their previous study ${ }^{[26]}$.

The addition of supporting materials may affect the conductivities of CPs. Another method to avoid conductivity loss was developed by coating CPs on pre-electrospun biomaterials nanofibres to create CPs nanofibre structures. The coatings of CPs were often carried out by 


\section{WILEY-VCH}

vapour phase chemical polymerization or solution chemical polymerization. In a study of PPy coated nanofibre, PLGA nano-meshes were firstly fabricated via electrospinning then put in pyrrole/pTS aqueous solution for chemical polymerization. The reaction was initiated by $\mathrm{FeCl}_{3}$ and kept for $24 \mathrm{~h}$ at $4^{\circ} \mathrm{C}$ to get PPy/PLGA meshes. The results of cell experiments showed that PPy/PLGA electrospun meshes enhanced the growth and differentiation of PC12 cells and hippocampal neurons comparable to non-coated PLGA control meshes. ES studies showed that PC12 cells, exhibited 40-50\% longer neurites and 40-90\% more neurite formation compared to unstimulated cells on the same scaffolds ${ }^{[83]}$.

While random CPs nanofibres showed promotion effect in nerve neurite outgrowth, the effect of aligned nanofibre on neurite extension guidance was studied by a group using vapour phase coated PPy on highly aligned nanofibres. Poly(styrene-b-isobutylene-b-sty-rene) (SIBS) and FepTS have been electrospun onto a gold coated mylar sheet in a sealed box containing pyrrole monomer vapour. PPy was polymerized on highly aligned SIBS/FepTS nanofibres via vapour phase polymerization during the electrospinning process. Cell experiments illustrated that neurite outgrowth from PC12 cells could be highly orientated parallel to the aligned PPy/SIBS fibres. Physical interactions between the nerve cells and PPy/SIBS fibres were observed using atomic force microscopy (Figure 11). These observations indicated a role of contact guidance as a mechanism for the observed alignment ${ }^{[28]}$.

Besides PANi and PPy, PEDOT electrospun nanofibres have also been investigated as nerve tissue engineering scaffolds. Electrospun PET nanofibres were coated with PEDOT/pTS using vapour phase polymerization. The nanofibres were good platforms for providing cells with a substrate for adhesion and proliferation. These conductive scaffolds were used to electrically stimulate $\mathrm{Ca}^{2+}$ signaling ${ }^{[36,95]}$ in SH-SY5Y nueroblastoma cells. Results showed that the combination of ES with highly porous and permeable 3D structures provided additional functionality to stimulate cells or record cell signaling ${ }^{[96]}$. 


\section{WILEY-VCH}

The increasing demands for combined and complicated interfacial stimulation promoted the incorporation of more functional molecules into nanofibres scaffold. Based on the PPy coated PLGA nanomesh discussed above ${ }^{[83]}$, NGF was chemically immobilized onto the surface of the fibres (Figure 12). These NGF immobilized PPy coated PLGA (NGF/PPy/PLGA) fibres supported PC12 neurite formation (28 $\pm 3 \%$ of the cells) and neurite outgrowth $(14.2 \mu \mathrm{m}$ median length), which were comparable to that observed with NGF (50 ng/mL) in culture medium $(29 \pm 1.3 \%, 14.4 \mu \mathrm{m})$. ES of PC12 cells on NGF immobilized PPy/PLGA fibre scaffolds was found to further improve neurite development and neurite length by $18 \%$ and $17 \%$, respectively, compared to unstimulated cells on the NGF immobilized fibres. Hence, sub-micrometre-scale fibrous scaffolds that incorporate neurotrophic and electroconductive activities may serve as promising neural tissue engineering scaffolds; such as nerve guidance conduits $^{[27]}$.

\subsubsection{CPs Nanotubes}

Another type of nanostructured CPs scaffold, CPs nanotubes, were designed by Abidian et al. to increase charge capacity density (CCD) for stronger and longer ES to nerve cells and decrease impedance for better neural signal recording. The hollow structure of nanotubes creates more surface areas compared to nanofibres, as well as films, allowing more surfaces for electrical charges storage ${ }^{[97]}$, which means high capacitance as well as CCD. The impedance of the CPs can be represented by the equation:

$$
\mathrm{Z}=\mathrm{R}+\mathrm{I}(\omega \mathrm{L}-1 / \omega \mathrm{C})
$$

Where $\mathrm{R}$ is resistance, $\mathrm{I}$ is current, $\mathrm{L}$ is inductance, $\mathrm{C}$ is capacitance and $\omega$ is a sinusoidal undulation frequency $^{[98]}$. Therefore, higher capacitance will lead to lower impedance from this equation. The PEDOT and PPy nanotubes were created via electrical deposition of CPs on pre-electrospun PLA nanofibres followed by removal of the PLA template by dissolving them in dichloromethane. Electrochemistry studies on impedance and charge capacity density (CCD) illustrated that PPy and PEDOT nanotubes have lower impedance and higher CCD in 


\section{WILEY-VCH}

comparison with their film counterparts. DRG cultured on CPs nanotubes exhibited longer neurites length than their film comparison samples. In addition, CPs nanotubes showed long term electrochemical stability in CV characterization, illustrating that it can serve as scaffolds in long term cell culture and ES experiments ${ }^{[99]}$.

\subsubsection{CPs Nanoporous Scaffold}

The exploitation of nanostructured conductive polymers, is hampered by their low solubility, poor mechanical integrity, and difficulty in fabrication. To improve the mechanical strength and retain the nanostructures, Cai et al. prepared electrically conductive nanoporous materials by coating nanoporous cellulose gels (NCG) with PPy. The resulting NCG/PPy composite hydrogels were converted to aerogels by drying with supercritical $\mathrm{CO}_{2}$, giving a density of $0.41-0.53 \mathrm{~g} \mathrm{~cm}^{-3}$, nitrogen adsorption surface areas of $264-303 \mathrm{~m}^{2} \mathrm{~g}^{-1}$, and high mechanical strength. In vitro studies showed that the incorporation of PPy into an NCG enhances the adhesion and proliferation of PC12 cells. ES demonstrated that PC12 cells attached and extended longer neurites when cultured on NCG/PPy composite gels with DBSA dopant ${ }^{[100]}$.

\subsubsection{CPs Microfibres Scaffold}

Besides, nanostructures, significant efforts have also been put into the development of electroactive hybrid scaffolds at the micrometre scale for the guidance of nerve cell migration and neurite outgrowth at certain directions. Nanostructures can create different surface morphologies and surface roughness to influence the cells at the nanometre scale while the micro-scale scaffold is comparable to a cell body size for the whole cell to attach and migrate along the scaffold.

Wet spinning microfibres conductive scaffold has been studied for its potential to control the multiple cues, such as topographic guidance, support, and ES to promote neurite directional growth. Biodegradable copolymer PLA:PLGA (75:25) was wet-spun into fibres (approximately $30 \mu \mathrm{m}$ in diameter), and aligned onto gold-coated mylar wrapped around a collector spool. The constructs were laid flat to facilitate the galvanostatic deposition of 


\section{WILEY-VCH}

PPy/pTS film, creating a thin layer of PPy/pTS between the biodegradable fibres. Scanning electron microscopy (SEM) confirmed the presence of the fibres embedded in the CPs layer (Figure 13 A-C). Dorsal root ganglia (DRG) explants cultured on this scaffold demonstrated axonal growth and Schwann cell migration followed the path of the polymer fibres on both stimulated and unstimulated platforms (Figure 13 E-G). ES enhanced the axonal growth significantly over $60 \%$ and promoted Schwann cell migration to some extent as well ${ }^{[18]}$.

Another study on the micrometre scale fibre scaffold utilized a blend of electrically conductive PANi and polypropylene (PP) composite fibres as the backbone of encapsulated nerve tissue engineering relays. Fibres with around $400 \mu \mathrm{m}$ diameter were manufactured by extrusion through a capillary rheometer and coated with collagen for DRG culture. A high density of neurons on the fibre surface (over 700 neurons $/ \mathrm{mm}^{2}$ ) was obtained and resulted in robust neurite extension and network formation. After that, this neuron network on fibre surface was encapsulated with agarose to form a protective barrier while potentially facilitating network stability (Figure 14). These efforts effectively created functional electrical interfaces for nerve cells and improved neurocompatibility, high density nerve cell adhesion and neurite network formation on micrometre scale fibre surfaces ${ }^{[19]}$.

\subsubsection{CPs Micro Patterns}

To combine the electrical and topographical cues for the stimulation of nerve cells, 2-D CPs micro-patterns have also been developed to function as tissue engineering scaffolds. Gomez et al created 1 and $2 \mu \mathrm{m}$ wide PPy micro channels using electron-beam (e-beam) lithography and electrical polymerization. Embryonic hippocampal neurons cultured on patterned PPy polarized (i.e., defined an axon) faster on the modified material, with a two-fold increase in the number of cells with axons compared to cells cultured on unmodified PPy (Figure 15). These topographical features also have an effect on axon orientation but do not have a significant effect on overall axon length ${ }^{[20]}$. 


\section{WILEY-VCH}

Micro-patterns can also be created by inkjet printing. Parallel PPy lines (100 $\mu \mathrm{m}$ width) have been deposited on biocompatible polymer substrate then covered by collagen using a Dimatix inkjet printer. PC 12 cells cultured on the substrate could be located on the surface of the micro lines and formed a neurite network. ES applied at the ends of the line can promote neurite outgrowth and guide the orientation of neurite extension along the printed PPy lines [21].

\subsubsection{D CPs Nerve Conduits}

To guide nerve tissues/cells recovery at lesion gaps, 3D PPy tubes were made via electrical deposition of PPy on wire template with different diameters. After the growth of PPy film, a reduction potential applied to the template allowed mechanical dissociation from the electrode template, creating a stand-alone PPy tube. Multichannel tubes were also fabricated via the same method. The obtained PPy nerve conduits were cut into $15 \mathrm{~mm}$ lengths and placed in transected rat sciatic nerves, and were shown to support nerve regeneration over an 8 -week time period $^{[101]}$

In summary, due to their inherent electrical conductive properties, reversible electrochemical properties, interfacial properties and their cyto-compatibility, CPs successfully provided all kinds of interfacial stimulations discussed above ${ }^{[22,102]}$. In detail, firstly CPs' highly conjugated carbon backbone and charge transfer ability allow them to provide direct ES to nerve tissues/cells cultured on their surface to significantly enhance neurite outgrowth; secondly, CPs can be doped with positively charged biomolecules and proteins for surface modification purposes which can improve cell adhesion properties and cell proliferation abilities; thirdly, CPs exhibit reversible electrochemical properties to allow the dopants to be released from the polymer chains, which illustrate the possibility of "release on demand" interfacial NTFs delivery in neuroregeneration; finally, their processability allow them to be formed into various geometries or patterns to get additional interfacial properties. Recent developments in micro- and nano-scale fabrication techniques of CPs, including laser beam, 


\section{WILEY-VCH}

electrospinning, wet spinning, and inkjet printing, create a series of nanofibres, nanotubes and micro dots and lines arrays to promote interaction between neural cells/tissues and materials surface.

The combined interfacial stimulations that CPs can provide made the foreground of CPs scaffolds in neuroregeneration quite promising. However, the barrier of transferring CPs into clinical ues from laboratory still existed. First of all, the electrochemical stabilities of CPs were not as reliable as needed which may result in the failures in interfacial NTFs delivery and ES. Environments including temperature, $\mathrm{pH}$ values, salts in tissue/cell culture mediums can all influence the electrochemical stabilities of CPs. The possible loss of dopants and fracture of polymer chains during ES may change the conductivity of the scaffold, which may lead to lower stimulation current and weak stimulation effects under the same potentials applied. The impendence of CPs would also increase for the same reasons and affected ES results or the signal recording results. To avoid this, ES of CPs should be applied in an appropriate range to make sure that CPs scaffolds were not overloaded under ES. The biodegradability of CPs would be another issue that did not achieve the standard of clinical utilization. CPs themselves were not degradable at all. Biodegradable CPs were most often created by coating CPs upon biodegradable polymers such as PLGA. The CPs layer broke into small pieces with PLGA degradation and the influence of these CPs residues remains unknown in vivo, which limited the applications of CPs in clinical application. In addition, a great many of CPs devices for neuroregeneration were fabricated via electrochemical methods, which is not suitable for massive production, limited the utilization of CPs in clinical as well.

\subsection{Bio-interface of Carbon nanotube and Graphene based materials in}

\section{Neuroregeneration}

Graphitic nanomaterials, such as carbon nanotubes (CNTs) and graphene, have gained a great deal of interests in the scientific communities due to their novel properties and wide range of 


\section{WILEY-VCH}

potential applications. As these graphitic materials hold similar but enhanced electrochemical properties in comparison with CPs, we also discuss the bio-interface effects in neuroregeneration that employed CNTs and Graphene based materials in this review.

Several early studies demonstrated CNTs were capable of serving as the scaffold in nerve tissue engineering and can offer ES to nerve cells that are cultured on the CNTs' surface ${ }^{[103]}$.Recent study on the cytotoxicity of CNTs and graphene illustrated that graphene is a better choice in nerve regeneration as it had lower cytotoxicity and better physical properties valued by PC 12 cells than single wall CNTs ${ }^{[104]}$. The promotion of nerve stimulation by a graphene substrate was studied using a mouse hippocampal culture model by $\mathrm{Li}$ et al.. The results revealed that graphene substrates exhibited excellent biocompatibility, as cell viability and morphology were not affected in comparison with the control specimen. In addition, neurite numbers and average neurite length on graphene were significantly enhanced during 2-7 days after cell seeding compared to tissue culture polystyrene (TCP) substrates ${ }^{[105]}$.

A 3-D graphene foam electrode has been recently reported as a promising candidate for nerve stem cell scaffold as it may incorporate topographical, chemical and electrical cues in the same scaffold to provide an environment for neural tissue regeneration that is superior to conventional inert biomaterials (Figure 16). It was found that three-dimensional graphene foams (3D-GF) can not only support NSCs growth, but also keep cells at an active proliferation state with regulation of Ki67 expression than that of two-dimensional graphene films. Meanwhile, phenotypic analysis indicated that 3D-GFs can enhance the NSCs differentiation towards astrocytes and especially neurons ${ }^{[106]}$.

In addition, CNTs and graphene based materials can enhance the properties of CPs in CPs/graphitic materials hybrid scaffold. CNT doped PEDOT showed an enhancement in electrical stability and conductivity compared to PEDOT, while neuron cellular activities were more or less the same ${ }^{[107]}$. PPy/graphene oxide (GO) composites demonstrated 


\section{WILEY-VCH}

significantly lower impedance than Pt electrode and pure PPy when used as neural probes materials ${ }^{[108]}$.

\section{Summary and Criteria}

The importance of bio-interface of polymer based biomaterials in neuroregeneration was proven by a series of investigations despite the existence of weakness and imperfection. To better clarify what kinds of criteria that an ideal biocompatible polymers interface should achieve, the advantages and disadvantages of current developed polymer scaffolds discussed above are summarized in Table 2.

We can easily conclude from Table 2 what are the properties that a successful biocompatible polymer scaffold should possess (Table 3). These biocompatible polymers should be biocompatible, biodegradable to ensure their long term clinical usage. In addition, these polymers should have specific physical, electrical, interfacial and biological properties to serve stably in a cell culture environment, provide interfacial ES, and interfacial delivery of NTFs to a lesion site when necessary. These criteria should be achieved by careful design and synthesis of the polymer scaffold which can successfully mimic an in vivo microenvironment, which is composed of cells, support scaffolds, growth factors and the extracellular matrix, and plays an important role in regulating neurogenesis, survival and regeneration of nerve cells ${ }^{[109]}$.

Flaws exist in nearly all current techniques more or less; such as synthetic biodegradable polymers' poor cell attachment ability and uncertain long term stability of CPs. The direction for future development of bio-interfaces of polymer based materials in our expectations is to address the criteria we concluded in Table 2 in a single scaffold; as many as possible. To achieve this target, tuning polymer properties using hybrid scaffold with multiple modification methods should be considered. For example, a novel scaffold like cell adhesion hydrogel coated NTFs modified CPs microfibres can combine ES, cell attachment ability and NTF delivery together for a complicated stimulation to nerve cells and tissues. 


\section{WILEY-VCH}

\section{Perspectives}

Success gained till now in the bio-interface of biocompatible polymers for neuroregeneration does not mean that the application of novel biocompatible polymer scaffolds clinically is just around the corner. Actually, some doubts still exist concerning this kind of material. For example, an often used method to create a biodegradable CPs scaffold is the coating of CPs on the outer surface of a biodegradable polymer such as PLGA. However, nobody has investigated about what happens after the CPs disintegrate with PLGA degradation; ie how will these small CPs pieces be discarded and excreted, in in vivo experiments. Also, whether these CPs pieces are completely unharmful to the human body is still in doubt. Another concern for CPs scaffolds in clinical use is their long-term stability, including both chemical stability in vivo and electrical stability to maintain ES for long period implantation. In addition, whether long term implantation of the CPs scaffold will result in rejection by the body has no conclusion either.

Thus we assume that in the recent future, investigations on the bio-interface of biocompatible polymer scaffolds will focus on the resolution of these problems to bridge the gaps between lab research activity and clinical application. In particular, the reliability of biomaterials in neuroregeneration needs to be evaluated more intensively before medical applications. The evaluation is not only to study the direct responses from animals but also to build reliable models for analysis, thus offering greater knowledge to rationally improve and/or redesign biomaterials. Composing novel engineered nanostructures or nanomaterials to enhance multifunctionality and/or reliability is another aspect that should be valued. Materials design and exploration is the key method to solve the problems that exist concerning biocompatibility/ biodegradability. More attention will be paid to long term in vivo compatibility testing of novel scaffolds, and the possibility of scalable massive commercial production of polymer scaffolds. The translation of research output to commercial therapy products will be the first priority in all. 


\section{WILEY-VCH}

\section{Acknowledgement}

This work is financially supported by Chongqing Key Laboratory for Advanced Materials and Technologies of Clean Energies under cstc2011pt-sy90001 (Chongqing, China), Start-up grant under SWU111071 from Southwest University (Chongqing, China) and Chongqing Science and Technology Commission under cstc2012gjhz90002 (Chongqing, China). The authors would also like to acknowledge the financial support of a $\mathrm{PhD}$ start-up grant SWU113111 from Southwest University (Chongqing, China) and the Fundamental Research Funds (XDJK2014C146) for the Central Universities and the help of proofreading from Assoc. Prof. Chee O. Too from University of Wollongong.

Received: ((will be filled in by the editorial staff))

Revised: ((will be filled in by the editorial staff))

Published online: ((will be filled in by the editorial staff)) 


\section{WILEY-VCH}

[1] L. J. Martin, Int. J. Mol. Med. 2001, 7, 455.

[2] a)A. J. Hughes, S. E. Daniel, L. Kilford, A. J. Lees, J. Neurol., Neurosurg. Psychiatry

1992, 55, 181; b)M. H. Polymeropoulos, C. Lavedan, E. Leroy, S. E. Ide, A. Dehejia, A.

Dutra, B. Pike, H. Root, J. Rubenstein, R. Boyer, science 1997, 276, 2045.

[3] a)J. P. Vonsattel, R. H. Myers, T. J. Stevens, R. J. Ferrante, E. D. Bird, E. P. Richardson

Jr., J. Neuropathol. Exp. Neurol. 1985, 44, 559; b)M. F. Beal, N. W. Kowall, D. W. Ellison,

M. F. Mazurek, K. J. Swartz, J. B. Martin, Nature 1986, 321, 168.

[4] a)W. G. Rosen, R. C. Mohs, K. L. Davis, Am. J. Psychiatry 1984, 141, 1356; b)J. Hardy, D. J. Selkoe, Science 2002, 297, 353.

[5] a)M. Donaghy, D. C. Lie, H. Song, S. A. Colamarino, G.-l. Ming, F. H. Gage, Annu. Rev. Pharmacol. Toxicol. 2004, 44, 399; b)P. L. McGeer, E. G. McGeer, Brain Res. Rev. 1995, 21 , 195; c)A. Bjorklund,O. Lindvall, Nat. Neurosci. 2000, 3, 537.

[6] a)E. R. Kandel, J. H. Schwartz, T. M. Jessell, Principles of Neural Science, McGraw-Hill Press 2000; b)G. Ming, H. Song, Annu. Rev. Neurosci. 2005, 28, 223.

[7] C. Profyris, S. S. Cheema, D. W. Zang, M. F. Azari, K. Boyle, S. Petratos, Neurobiol. Dis. 2004, 15,415 .

[8] a)M. Donaghy, Brain's diseases of the nervous system, Oxford University Press New York, 2001; b)P. Kleihues, W. K. Cavenee, Pathology and genetics of tumours of the nervous system, International Agency for Research on Cancer 2000; c)R. T. Johnson, Viral infections of the nervous system, Lippincott-Raven Publishers 1998.

[9] T. C. Burns, C. M. Verfaillie, W. C. Low, J. Comp. Neurol. 2009, 515, 125.

[10] R. J. Armstrong, R. A. Barker, The Lancet 2001, 358, 1174.

[11] J. Chen, M. Chopp, NeuroRx, J. Am. Chem. Soc. 2006, 3, 466. 


\section{WILEY-VCH}

[12] R. A. Barker, S. B. Dunnett. Neural repair, transplantation andrehabilitation. Hove, UK:

Psychology Press 1999.

[13] a)Z. Xiaobo, Mater. Rev. 2003, 5, 017; b)K. Saha, E. F. Irwin, J. Kozhukh, D. V.

Schaffer and K. E. Healy, J. Biomed. Mater. Res., Part A 2007, 81, 240.

[14] P. J. Camarata, R. Suryanarayanan, D. A. Turner, R. G. Parker, T. J. Ebner,

Neurosurgery 1992, 30, 313.

[15] P. Menei, V. Daniel, C. Montero-Menei, M. Brouillard, A. Pouplard-Barthelaix, J. P. Benoit, Biomaterials 1993, 14, 470.

[16] J. Lee, M. J. Cuddihy, N. A. Kotov, Tissue Eng., Part B 2008, 14, 61.

[17] a)G. R. Evans, K. Brandt, S. Katz, P. Chauvin, L. Otto, M. Bogle, B. Wang, R. K.

Meszlenyi, L. Lu, A. G. Mikos, Biomaterials 2002, 23, 841; b)G. Evans, K. Brandt, M.

Widmer, L. Lu, R. Meszlenyi, P. Gupta, A. Mikos, J. Hodges, J. Williams, A. Gürlek,

Biomaterials 1999, 20, 1109; c)G. R. Evans, K. Brandt, A. D. Niederbichler, P. Chauvin, S.

Hermann, M. Bogle, L. Otta, B. Wang, C. W. Patrick, J. Biomater. Sci. Polym. Ed. 2000, 11, 869.

[18]A. F. Quigley, J. M. Razal, B. C. Thompson, S. E. Moulton, M. Kita, E. L. Kennedy, G.

M. Clark, G. G. Wallace, R. M. Kapsa, Adv. Mater. 2009, 21, 4393.

[19] D. Cullen, A. R Patel, J. Doorish, D. Smith, B. Pfister, J. Neural Eng. 2008, 5, 374.

[20] N. Gomez, J. Lee, J. Nickels, C. Schmidt, Adv. Funct. Mater. 2007, 17, 1645.

[21] a)B. Weng, X. Liu, R. Shepherd, G. Wallace, Synth. Met. 2012; b)B. Weng, X. Liu, M.

Higgins, R. Shepherd, G. Wallace, Small 2011, 7, 3434.

[22] C. Schmidt, V. Shastri, J. Vacanti, R. Langer, Proc. Natl. Acad. Sci. U. S. A 1997, 94, 8948.

[23] R. Green, N. Lovell, L. Poole-Warren, Acta Biomater. 2010, 6, 63.

[24] A. Sanghvi, K. Miller, A. Belcher, C. Schmidt, Nat. Mater. 2005, 4, 496. 


\section{WILEY-VCH}

[25] H. K. Song, B. Toste, K. Ahmann, D. Hoffman-Kim, G. Palmore, Biomaterials 2006, 27, 473.

[26] M. Prabhakaran, L. Ghasemi-Mobarakeh, G. Jin, S. Ramakrishna, J. Biosci. Bioeng. 2011, 112, 501 .

[27] J. Lee, C. Bashur, C. Milroy, L. Forciniti, A. Goldstein, C. Schmidt, IEEE T. Nnobiosci. 2012, 11, 15.

[28] X. Liu, J. Chen, K. Gilmore, M. Higgins, Y. Liu, G. Wallace, J. Biomed. Mater. Res., Part A 2010, 94, 1004.

[29] Y. Wang, Y. Wei, Z. Zu, R. Ju, M. Guo, X. Wang, Q. Xu, F. Cui, Pharm. Res. 2011, 28, 1406.

[30] a)S. Hou, Q. Xu, W. Tian, F. Cui, Q. Cai, J. Ma, I.-S. Lee, J. Neurosci. Methods 2005, 148, 60; b)S. Hou, W. Tian, Q. Xu, F. Cui, J. Zhang, Q. Lu, C. Zhao, J. Neurosci. 2006, 137, 519.

[31] A. Gelmi, M. Higgins, G. Wallace, Biomaterials 2010, 31, 1974.

[32] a)A. Piotrowicz, M. Shoichet, Biomaterials 2006, 27, 2018; b)X. Xu, W.-C. Yee, P. Hwang, H. Yu, A. Wan, S. Gao, K.-L. Boon, H.-Q. Mao, K. Leong, S. Wang, Biomaterials 2003, 24, 2405; c)Y. Yang, L. De Laporte, C. Rives, J.-H. Jang, W.-C. Lin, K. Shull, L. Shea, J. Controlled Release 2005, 104, 433.

[33] a)C.-J. Chang, S.-H.Hsu, Biomaterials 2006, 27, 1035; b)S. Oh, J. Lee, J. Biomed. Mater. Res., Part A 2007, 80, 530.

[34] a)B. Bruno, G. Stefano, F. Matteo, T. Pierluigi, Microsurgery 2005, 25; b)R. Weber, W. Breidenbach, R. Brown, M. Jabaley, D. Mass, Plast. Reconstr. Surg. 2000, 106, 1036.

[35] L. Pfister, E. Alther, M. Papaloïzos, H. Merkle, B. Gander, Eur. J. Pharm. Biopharm. 2008, 69, 563.

[36] Y. Ogawa, H. Okada, T. HEYA, T. SHIMAMOTO, J. Pharm. Pharmacol. 1989, 41, 439. 


\section{WILEY-VCH}

[37] a)R. Gurny, N. Peppas, D. Harrington, G. Banker, Drug Dev. Ind. Pharm. 1981, 7, 1;

b)J.-M.Ruiz, J.-P.Busnel, J.-P.Benoît, Pharm. Res. 1990, 7, 928; c)R. A. Kenley, M. O. Lee,

T. R. Mahoney, L. M. Sanders, Macromolecules 1987, 20, 2398.

[38] a)J. Péan, M. Venier-Julienne, F. Boury, P. Menei, B. Denizot, J. Benoit, J. Controlled Release 1998, 56, 175; b)R. de Boer, A. Knight, R. Spinner, M. Malessy, M. Yaszemski, A. Windebank, J. Biomed. Mater. Res., Part A 2010, 95, 1067.

[39] J.-M. Lü, X. Wang, C. Marin-Muller, H. Wang, P. Lin, Q. Yao, C. Chen, Expert Rev. Mol. Diagn. 2009, 9, 325.

[40] L. Novikova, J. Pettersson, M. Brohlin, M. Wiberg, L. Novikov, Biomaterials 2008, 29, 1198.

[41] S. Mittal, A. Cohen, D. Maysinger, Neuroreport 1994, 5, 2577.

[42] a)G. Marie, P. Isabelle, B. François, Biomaterials 2003, 24; b)M. Cheng, J. Deng, F. Yang, Y. Gong, N. Zhao, X. Zhang, Biomaterials 2003, 24, 2871.

[43] a)S. Madduri, K. Feldman, T. Tervoort, M. Papaloïzo, J. Controlled Release 2010, 143, 168; b)G. Evans, K. Brandt, S. Katz, P. Chauvin, L. Otto, M. Bogle, B. Wang, R. Meszlenyi, L. Lu, A. Mikos, C. Patrick, Biomaterials 2002, 23, 841; c)C. Sundback, T. Hadlock, M.

Cheney, J. Vacanti, Biomaterials 2003, 24, 819; d)Y. Yang, X. Gu, R. Tan, W. Hu, X. Wang, P. Zhang, T. Zhang, Biotechnol. Lett. 2004, 26, 1793.

[44] L. Pfister, M. Papaloïzos, H. Merkle, B. Gander, JPNS, J. Peripher. Nerv. Syst. 2007, 12, 65.

[45] J. Braga-Silva, J. Hand. Surg. (Edinburgh, Scotland) 1999, 24, 703.

[46] T. Hadlock, C. Sundback, D. Hunter, M. Cheney, J. Vacanti, Tissue Eng. 2000, 6, 119.

[47] R. Fields, J. Le Beau, F. Longo, M. Ellisman, Prog. Neurobiol. 1989, 33, 87.

[48] G. Lundborg, L. Dahlin, N. Danielsen, R. Gelberman, F. Longo, H. Powell, S. Varon, Exp. Neurol. 1982, 76, 361. 


\section{WILEY-VCH}

[49] a)R. Young, M. Wiberg, G. Terenghi, Br. J. Plast. Surg. 2002, 55, 235; b)A. Mosahebi,

M. Wiberg, G. Terenghi, Tissue Eng. 2003, 9, 209.

[50] a)S. Itoh, M. Masumi, I. Yamaguchi, K. Takakuda, H. Kobayashi, K. Shinomiya J.

Tanaka, Artif. Organs 2003, 27,1079; b)I. Yamaguchi, S. Itoh, M. Suzuki, A. Osaka, J.

Tanaka, Biomaterials 2003, 24, 3285.

[51] a)P. Dalton, L. Flynn, M. Shoichet, Biomaterials 2002, 23, 3843; b)J. Belkas, C. Munro,

M. Shoichet, R. Midha, Restor. Neurol. Neurosci. 2005, 23, 19.

[52] M. Borkenhagen, R. Stoll, P. Neuenschwander, U. Suter, P. Aebischer, Biomaterials 1998, 19, 2155.

[53] S. Madduri, K. Feldman, T. Tervoort, M. Papaloïzos, B. Gander, J. Controlled Release 2010, 143, 168.

[54] T. Nakamura, Y. Inada, S. Fukuda, M. Yoshitani, A. Nakada, S. Itoi, S. Kanemaru, K. Endo, Y. Shimizu, Brain Res. 2004, 1027, 18.

[55] a)E. Goldensohn, Electroencephalogr. Clin. J. Neurophysiol. 1998, 106, 94; b)H.

Kettenmann, Trends Neurosci. 1997, 20, 239; c)M. A. B. Brazier, J. Neurophysiol. 1957, 20, 212.

[56] a)J. Ranck, Brain Res. 1975, 98, 417; b)D. Pfaff, M. Keiner, J. Comp. Neurol. 1973, 151, 121; c)B. Gustafsson, E. Jankowska, J. Physiol. 1976, 258, 33; d)H. Chang, J. Neurophysiol. 1951, $14,1$.

[57] a)P. Aebischer, R. F. Valentini, P. Dario, C. Domenici, P. M. Galletti, Brain Res. 1987, 436, 165; b)R. F. Valentini, T. G. Vargo, J. A. Gardella Jr, P. Aebischer, Biomaterials 1992, 13, 183; c)R. Valentini, A. Sabatini, P. Dario, P. Aebischer, Brain Res. 1989, 480, 300. [58] a)B. Sisken, M. Kanje, G. Lundborg, E. Herbst, W. Kurtz, Brain Res. 1989, 485, 309; b)J. Kerns, A. Fakhouri, H. Weinrib, J. Freeman, J. Neurosci. 1991, 40, 93; c)P. J. Basser, IEEE T. Biomed. Eng. 1994, 41, 601. 


\section{WILEY-VCH}

[59] T. Sekitani, Y. Noguchi, K. Hata, T. Fukushima, T. Aida and T. Someya, Science, 2008, 321, 1468.

[60] X. Cui, J. Wiler, M. Dzaman, R. A. Altschuler and D. C. Martin, Biomaterials, 2003, 24, 777.

[61] a)C. Chiang, C. Fincher Jr, Y. Park, A. Heeger, H. Shirakawa, E. Louis, S. Gau, A.

MacDiarmid, Phys. Rev. Lett. 1977, 39, 1098; b)H. Shirakawa, E. Louis, A. MacDiarmid, C.

Chiang, A. Heeger, J. Chem. Soc., Chem. Commun. 1977, 1977, 578.

[62] R. L. Williams, P. J. Doherty, J. Mater. Sci.: Mater. Med. 1994, 5, 429.

[63] P. Bidez, S. Li, A. Macdiarmid, E. Venancio, Y. Wei, P. Lelkes, J. Biomater. Sci. Polym. Ed. 2006, 17, 199.

[64] S. Kamalesh, P. Tan, J. Wang, T. Lee, E. Kang, C. Wang, J. Biomed. Mater. Res. 2000, $52,467$.

[65] B. Thompson, S. Moulton, J. Ding, R. Richardson, A. Cameron, S. O'Leary, G. Wallace, G. Clark, J. Controlled Release 2006, 116, 285.

[66] R. Richardson, B. Thompson, S. Moulton, C. Newbold, M. Lum, A. Cameron, G.

Wallace, R. Kapsa, G. Clark, S. O'Leary, Biomaterials 2007, 28, 513.

[67] A. Evans, B. Thompson, G. Wallace, R. Millard, S. O'Leary, G. Clark, R. Shepherd, R. Richardson, J. Biomed. Mater. Res., Part A 2009, 91, 241.

[68] R. Richardson, A. Wise, B. Thompson, B. Flynn, P. Atkinson, N. Fretwell, J. Fallon, G. Wallace, R. Shepherd, G. Clark, S. O'Leary, Biomaterials 2009, 30, 2614.

[69] B. Thompson, R. Richardson, S. Moulton, A. Evans, S. O'Leary, G. Clark, G. Wallace, J. Controlled Release 2010, 141, 161.

[70] B. Thompson, S. Moulton, R. Richardson, G. Wallace, Biomaterials 2011, 32, 3822.

[71] D. H. Kim, S. M. Richardson-Burns, J. L. Hendricks, C. Sequera, D. C. Martin, $A d v$. Funct. Mater. 2007, 17, 79. 


\section{WILEY-VCH}

[72] P. M. George, D. A. LaVan, J. A. Burdick, C. Y. Chen, E. Liang, R. Langer, Adv. Mater. 2006, 18, 577.

[73] N. Gomez, C. Schmidt, J. Biomed. Mater. Res., Part A 2007, 81, 135.

[74] J. Lee, J.-W. Lee, C. Schmidt, J. Roy. Soc. Interface 2009, 6, 801.

[75]M.J. Higgins, P. J. Molino, Z. Yue, G. G. Wallace, Chem. Mater. 2012, 24, 828.

[76] X. Liu, Z. Yue, M. J. Higgins, G. G. Wallace, Biomaterials 2011, 32, 7309.

[77] a)J. Fonner, L. Forciniti, H. Nguyen, J. Byrne, Y.-F. Kou, J. Syeda-Nawaz, C. Schmidt, J. Biomed. Mater. 2008, 3, 34124; b)M. Asplund, H. von Holst, O. Inganäs, Biointerphases 2008, 3, 83; c)X. Liu, K. Gilmore, S. Moulton, G. Wallace, J. Neural Eng. 2009, 6, 65002; d)B. Garner, A. Georgevich, A. Hodgson, L. Liu, G. Wallace, J. Biomed. Mater. Res. 1999, 44, 121.

[78] a)L. Poole-Warren, N. Lovell, S. Baek, R. Green, Expert Rev. Med. Devices 2010, 7, 35; b)A. Subramanian, U. Krishnan, S. Sethuraman, J. Biomed. Sci. 2009, 16, 108; c)R. Ravichandran, S. Sundarrajan, J. Venugopal, S. Mukherjee, S. Ramakrishna, J. Roy. Soc. Interface 2010, 7, 79.

[79]J. H. Collier, J. P. Camp, T. W. Hudson, C. E. Schmidt, J. Biomed. Mater. Res. 2000, 50, 574.

[80] S. Meng, M. Rouabhia, G. Shi, Z. Zhang, J. Biomed. Mater. Res., Part A 2008, 87, 332.

[81] J. Huang, X. Hu, L. Lu, Z. Ye, Q. Zhang, Z. Luo, J. Biomed. Mater. Res., Part A 2010, 93, 164.

[82] H. Durgam, S. Sapp, C. Deister, Z. Khaing, E. Chang, S. Luebben, C. Schmidt, J. Biomater. Sci. Polym. Ed. 2010, 21, 1265.

[83] J. Lee, C. Bashur, A. Goldstein, C. Schmidt, Biomaterials 2009, 30, 4325.

[84] a)P. Moroder, M. Runge, H. Wang, T. Ruesink, L. Lu, R. Spinner, A. Windebank, M. Yaszemski, Acta Biomater. 2011, 7, 944; b)M. Runge, M. Dadsetan, J. Baltrusaitis, A. Knight, T. Ruesink, E. Lazcano, L. Lu, A. Windebank, M. Yaszemski, Biomaterials 2010, 31, 5916. 


\section{WILEY-VCH}

[85] M. B. Runge, M. Dadsetan, J. Baltrusaitis, T. Ruesink, L. Lu, A. J. Windebank, M. J. Yaszemski, Biomacromolecules 2010, 11, 2845.

[86] Z. Zhang, M. Rouabhia, Z. Wang, C. Roberge, G. Shi, P. Roche, J. Li, L. Dao, Artif. Organs 2007, 31, 13.

[87] G. Shi, M. Rouabhia, Z. Wang, L. Dao, Z. Zhang, Biomaterials 2004, 25, 2477.

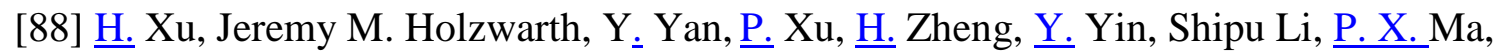
Biomaterials 2014, 35, 225.

[89] F. Keohan, X. Wei, A. Wongsarnpigoon, E. Lazaro, J. Darga, W. Grill, J. Biomater. Sci. Polym. Ed. 2007, 18, 1057.

[90] A. Fabbro, M. Prato b, L. Ballerini, Adv. Drug Deliver. Rev. 2013, 65, 2034.

[91] T. Dvir, B.P. Timko, D.S. Kohane, R. Langer, Nat. Nanotechnol. 2011, 6, 13.

[92] a) B. Geiger, J.P. Spatz, A.D. Bershadsky, Rev. Mol. Cell Biol. 2009, 10, 23; b) J.P. Myers, M. Santiago-Medina, T.M. Gomez, Dev. Neurobiol. 2011, 71, 901; c) S.D. Skaper, Methods Mol. Biol. 2012, 846, 13.

[93] a) M. Arnold, E.A. Cavalcanti-Adam, R. Glass, J. Blümmel, W. Eck, M. Kantlehner, H. Kessler, J.P. Spatz, Chemphyschem 2004, 5, 383; b) V. Brunetti, G. Maiorano, L. Rizzello, B. Sorce, S. Sabella, R. Cingolani, P. P. Pompa, Proc. Natl. Acad. Sci. U. S. A. 2010, 107, 6264. [94] L. Ghasemi-Mobarakeh, M. Prabhakaran, M. Morshed, M. Nasr-Esfahani, S. Ramakrishna, Tissue Eng., Part A 2009, 15, 3605.

[95] J. Isaksson, P. Kjäll, D. Nilsson, N. Robinson, M. Berggren, A. Richter-Dahlfors, Nat. Mater. 2007, 6, 673.

[96] M. H. Bolin, K. Svennersten, X. Wang, I. S. Chronakis, A. R. Dahlfors, E. W. H. Jager and M. Berggren, Sens. Actuators, B 2009, 142, 451.

[97] S. Chen, J. Zhu, X. Wu, Q. Han, X. Wang, ACS nano 2010, 4, 2822.

[98] J. R. Macdonald, E. Barsoukov, History, 2005, 1, 8.

[99] M. Abidian, J. Corey, D. Kipke, D. Martin, Small 2010, 6, 421. 


\section{WILEY-VCH}

[100] Z. Shi, H. Gao, J. Feng, B. Ding, X. Cao, S. Kuga, Y. Wang, L. Zhang, J.Cai, Angew. Chem. 2014, 126, 5484.

[101] P. George, R. Saigal, M. Lawlor, M. Moore, D. LaVan, R. Marini, M. Selig, M. Makhni, J. Burdick, R. Langer, D. Kohane, J. Biomed. Mater. Res., Part A 2009, 91, 519.

[102] a)J. Y. Wong, R. Langer, D. E. Ingber, Proc. Natl. Acad. Sci. 1994, 91, 3201; b)A.

MacDiarmid, J. Chiang, A. Richter, A. Epstein, Synth. Met. 1987, 18, 285.

[103] a)P. Galvan-Garcia, E. Keefer, F. Yang, M. Zhang, S. Fang, A. Zakhidov, R. Baughman, M. Romero, J. Biomater. Sci. Polym. Ed. 2007, 18, 1245; b)R. A. Dubin, G. C. Callegari, J. Kohn, A. V. Neimark, IEEE T. NanoBiosci. 2008, 7, 11; c)H. Hu, Y. Ni, V. Montana, R. C. Haddon, V. Parpura, Nano Lett. 2004, 4, 507; d)M. P. Mattson, R. C. Haddon, A. M. Rao, J. Mol. Neurosci. 2000, 14, 175; e)E. Jan, N. Kotov, Nano Lett. 2007, 7, 1123.

[104] Y. Zhang, S. Ali, E. Dervishi, Y. Xu, Z. Li, D. Casciano, A. Biris, ACS nano 2010, 4, 3181.

[105] N. Li, X. Zhang, Q. Song, R. Su, Q. Zhang, T. Kong, L. Liu, G. Jin, M. Tang, G. Cheng, Biomaterials 2011, 32, 9374.

[106] N. Li, Q. Zhang, S. Gao, Q. Song, R. Huang, L. Wang, L. Liu, J. Dai, M. Tang, G. Cheng, Sci. Rep. 2013, 3, 1604.

[107] X. Luo, C. Weaver, D. Zhou, R. Greenberg, X. Cui, Biomaterials 2011, 32, 5551.

[108] D. Meng, Y. Xi, S. Musa, Q. Weiming, X. Mingsheng, B. Gustaaf, C. Hongzheng, Sens. Actuators, B 2011, 158.

[109] a)P. A. Walker, K. R. Aroom, F. Jimenez, S. K. Shah, M. T. Harting, B. S. Gill, C. S. Cox Jr, Stem Cell Rev. Rep. 2009, 5, 283; b)L. Little, K. E. Healy, D. Schaffer, Chem Rev. 2008, 108, 1787. 
(a)

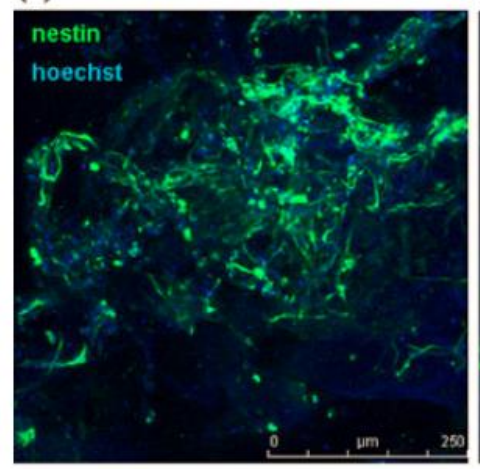

(b)

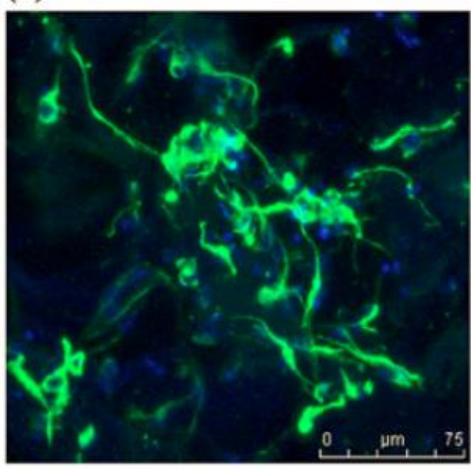

(c)

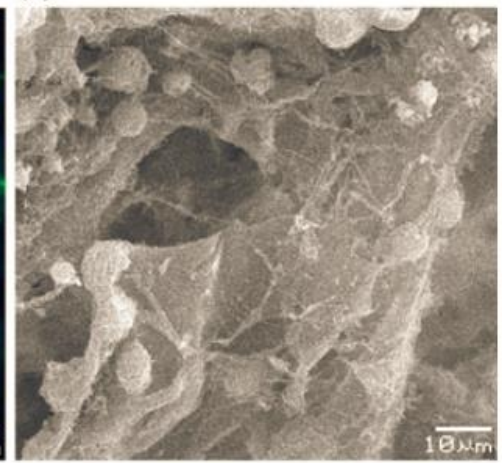

(d)

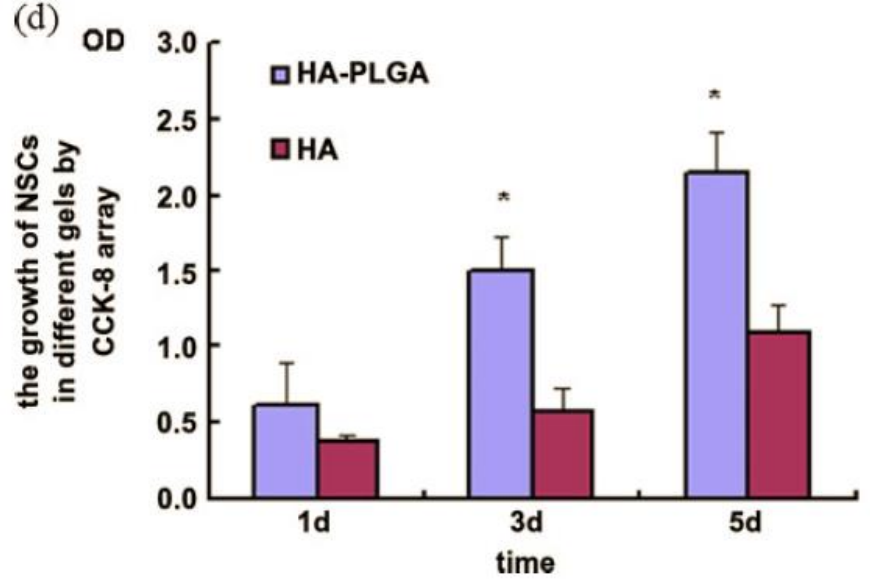

Figure 1. The growth of NSCs on the HA hydrogel composite for 5 days. (a, b) The fluorescent staining of nestin showed the NSCs (green) adhered on the gel, grew well and spread widely along the wall of the scaffold (a overall view), extending long neurites (b, high magnification). (c) The hydrogel showed good biocompatibility and support for NSCs by SEM. (d) The proliferation array by CCK-8 showed the NSCs grew faster on the hydrogel composite than on the HA hydrogel control $(* \mathrm{p}<0.05)^{[29]}$. 


\section{WILEY-VCH}

A

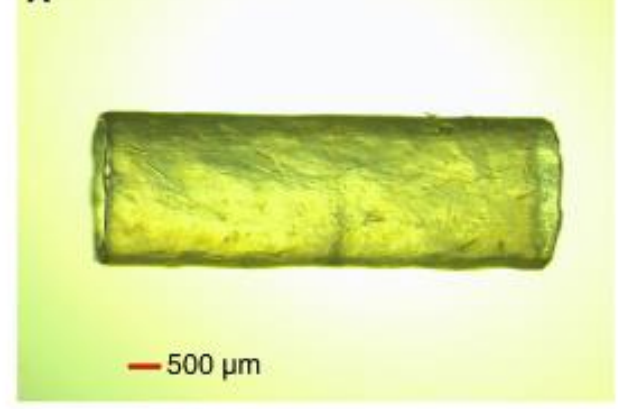

B

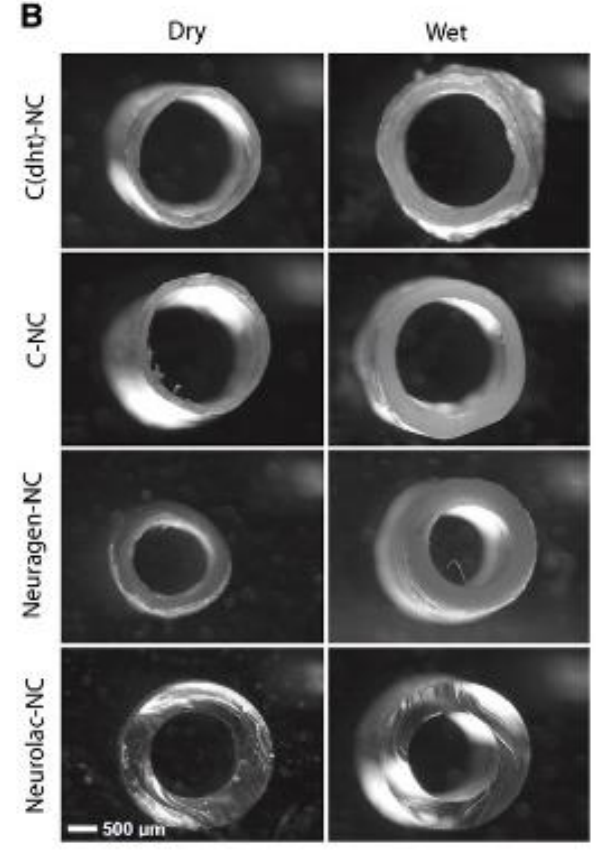

Figure 2. A) Micrograph of a typical NC (10 x magnification). B) Micrographs of crosssections of NC in the dry state and after swelling to equilibrium $(20 \mathrm{x} \text { magnification })^{[53]}$.
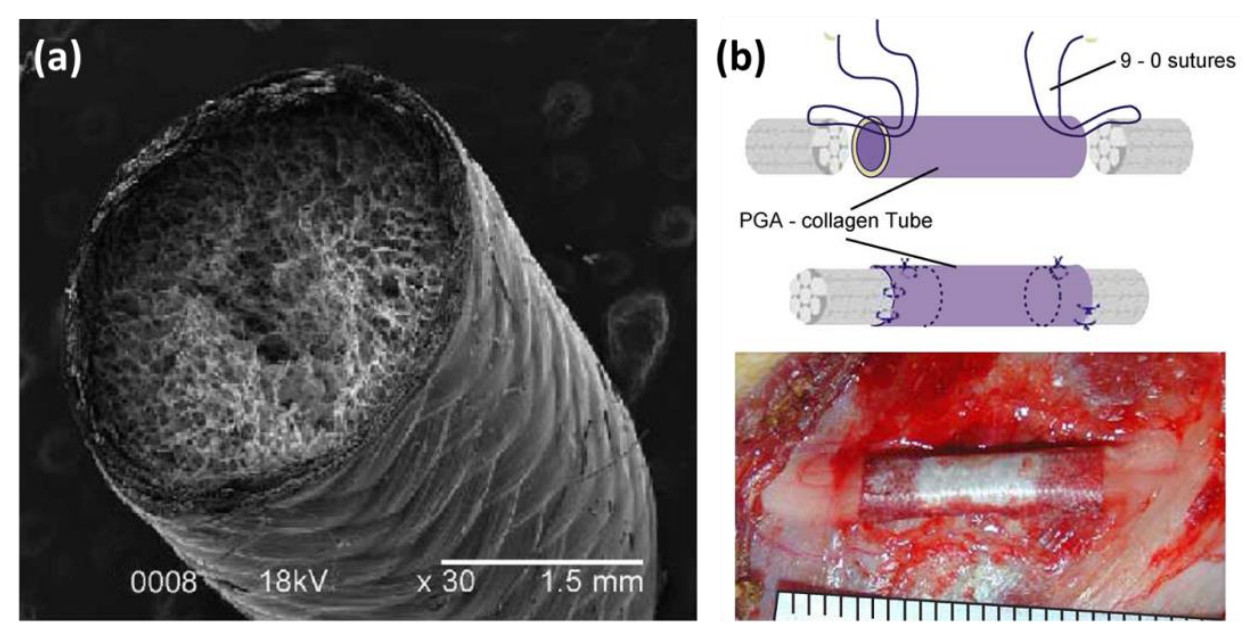

Figure 3. (a) Scanning electron micrograph of the nerve conduit which consists of a PGAcollagen tube filled with collagen sponge; (b) Suture methods and intraoperative view after implantation of a PGA-collagen tube ${ }^{[54]}$. 


\section{WILEY-VCH}

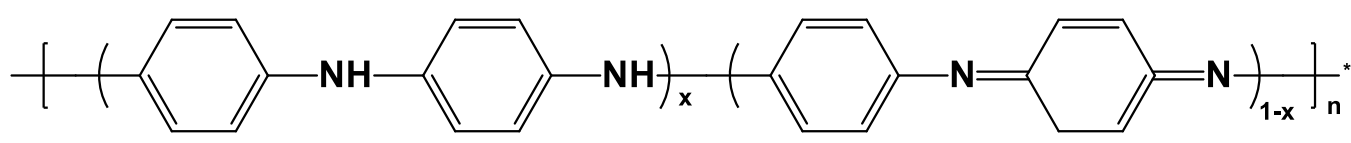

(a)<smiles>CC(C)(C)c1ccc(-c2ccc(-c3ccc(-c4ccc(C(F)(F)F)[nH]4)[nH]3)[nH]2)[nH]1</smiles>

(b)

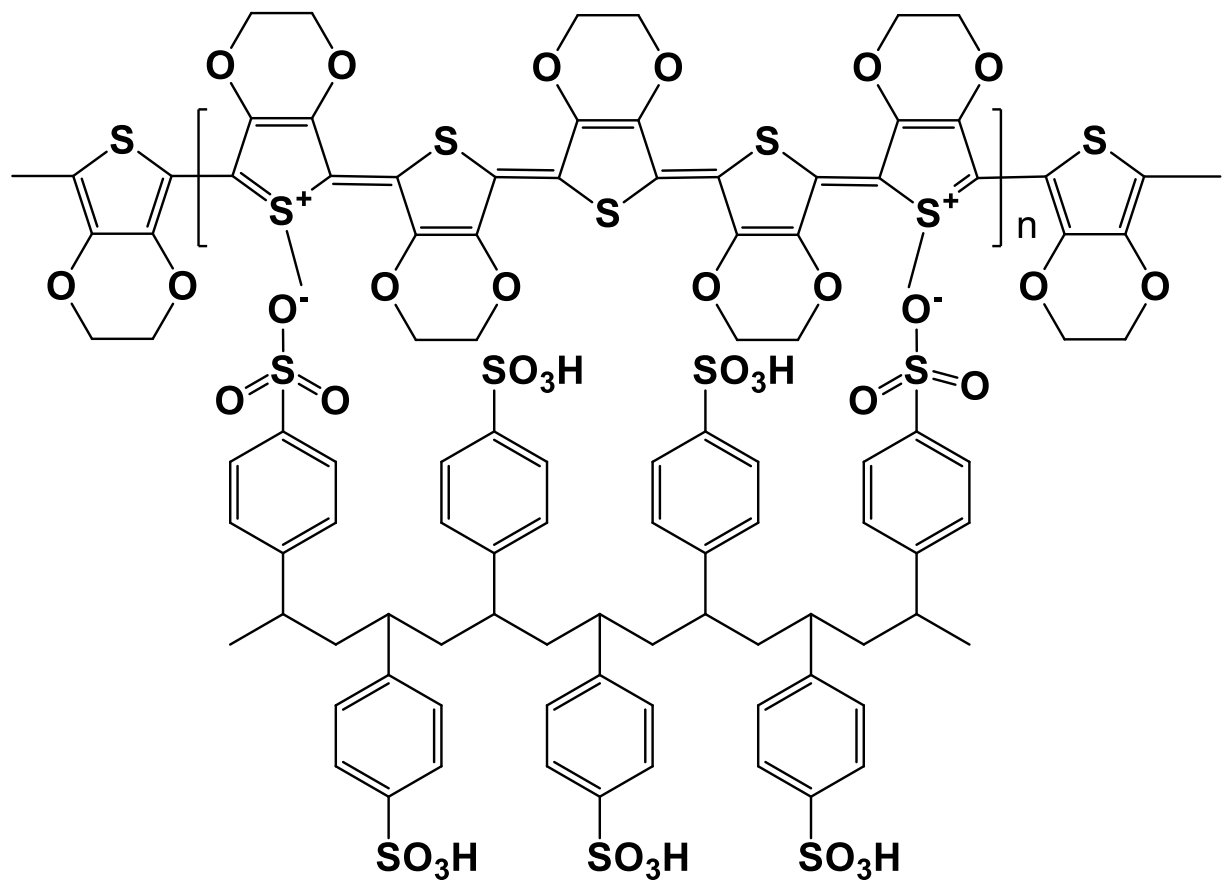

(c)

Figure 4. Chemical structures of (a) PANi; (b) PPy and (c)PEDOT-PSS 


\section{WILEY-VCH}
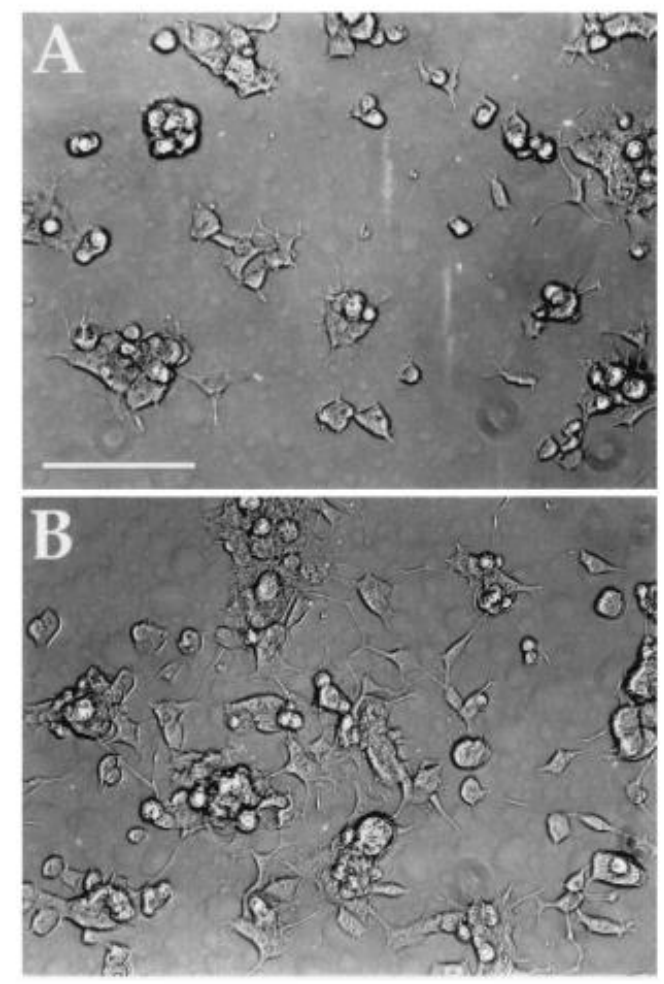

Figure 5. PC 12 cell differentiation on polypyrrole without (A) and with (B) application of an electric potential. Bar $=100 \mu \mathrm{m}^{[22]}$. 

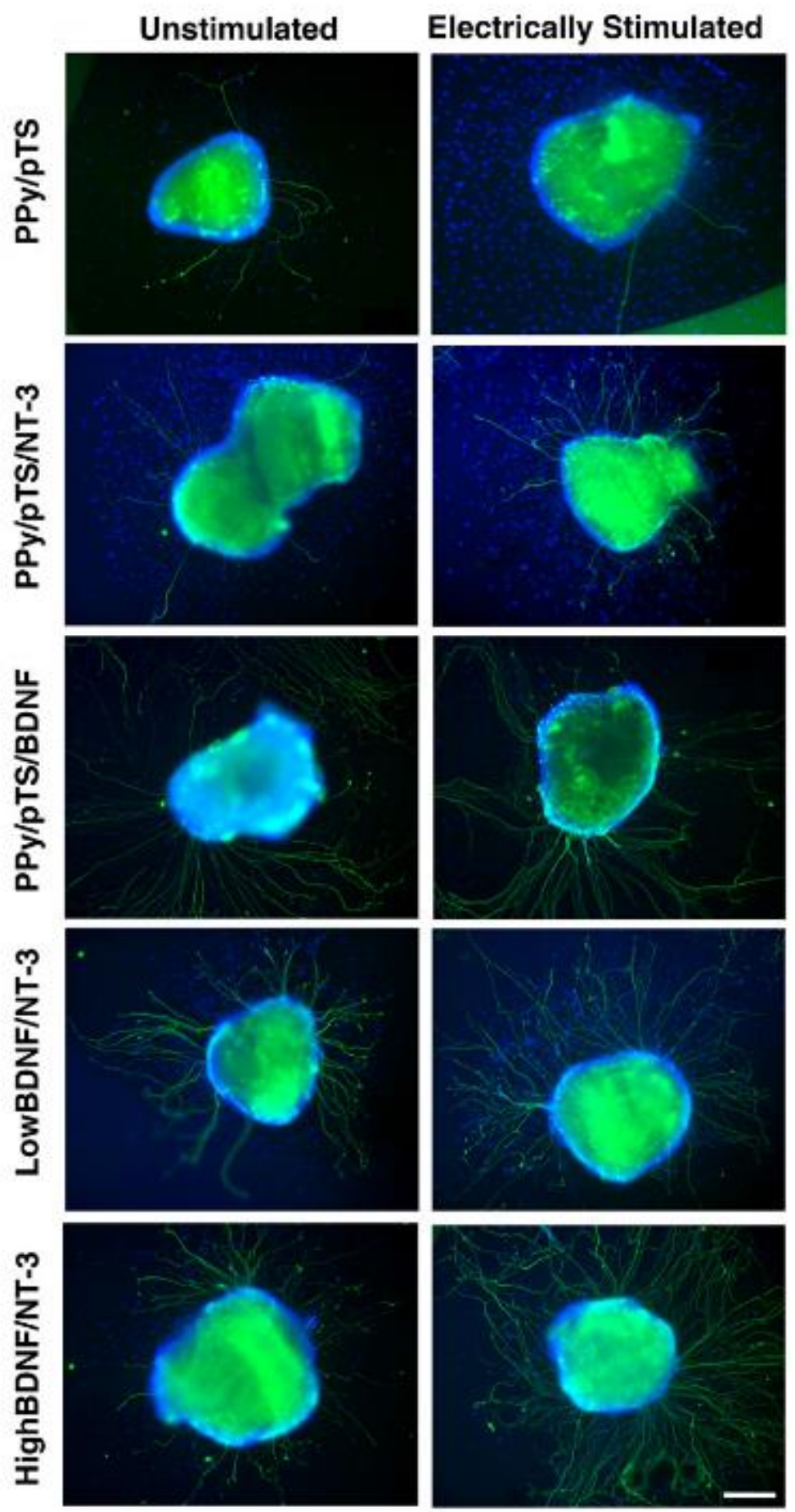

Figure 6. Representative images of cochlear neural explants grown on PPy/pTS polymers with and without neurotrophin. Neurites were visualised by immunocytochemistry with a neurofilament-200 primary antibody and a fluorescent secondary antibody (green). Cell nuclei are labelled with DAPI (blue). In the absence of neurotrophin (PPy/pTS), very few neurites were observed from explants, while explants grown on PPy/pTS containing neurotrophin demonstrated increased numbers of sprouting neurites. A greater number of neurites per explant were observed on explants grown on the electrically stimulated PPy films (right). These images were taken after 4 days of explants culture. Scale bar is $200 \mu \mathrm{m}$ and the same for all images ${ }^{[69]}$. 


\section{WILEY-VCH}

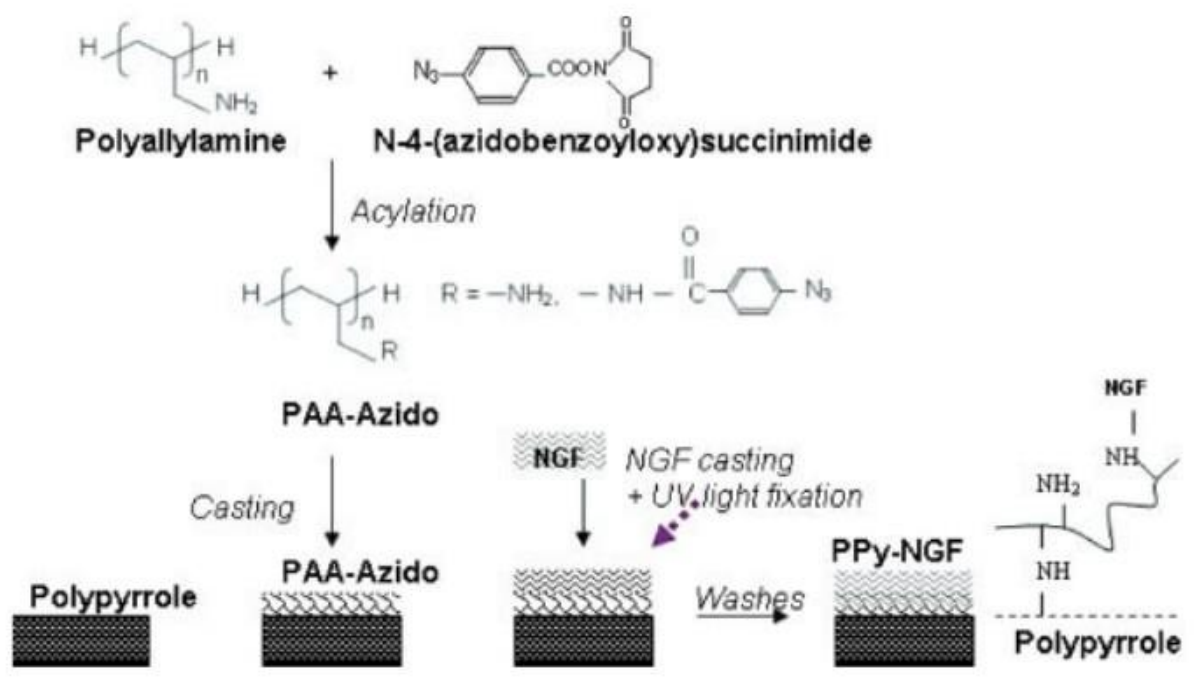

Figure 7. Scheme of the NGF immobilization process. PAA was conjugated to an azido compound (PAA-azido). This conjugate was cast twice on PPy, followed by casting of NGF. UV light exposure promoted the formation of covalent bonds via the azido groups, immobilizing NGF to PPy ${ }^{[73]}$.
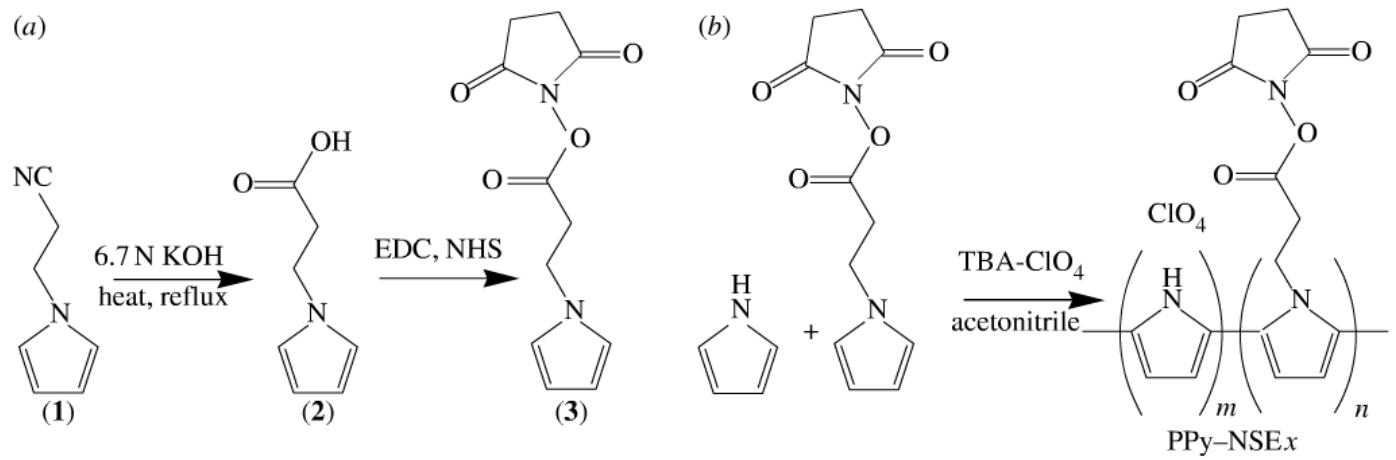

Figure 8. (a) Schematic of the pyrrole-NSE synthesis (3). 1-(2-Cyanoethyl)pyrrole (1) was converted to 1-(2-carboxyethyl)pyrrole (2), followed by the NHS substitution at the carboxyl group. (b) Electrochemical synthesis of the copolymers of pyrrole and pyrrole-NSE in acetonitrile with tetrabutylammonium perchlorate $\left(\mathrm{TBA}^{-} \mathrm{ClO}_{4}\right)$ as the dopant. PPy/NSEx indicates the copolymer which is synthesized with $\mathrm{x}$ mol\% of pyrrole-NSE from a $50 \mathrm{mM}$ total monomer concentration in the polymerizing solution ${ }^{[74]}$. 


\section{WILEY-VCH}

(a)

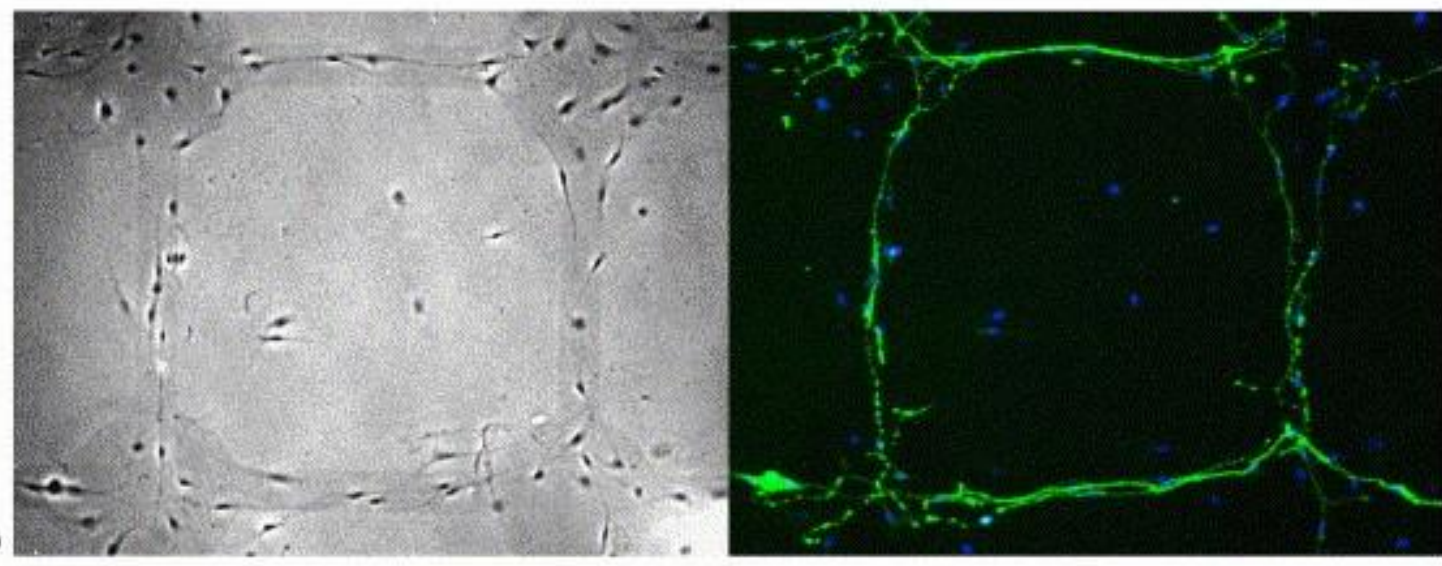

(b)

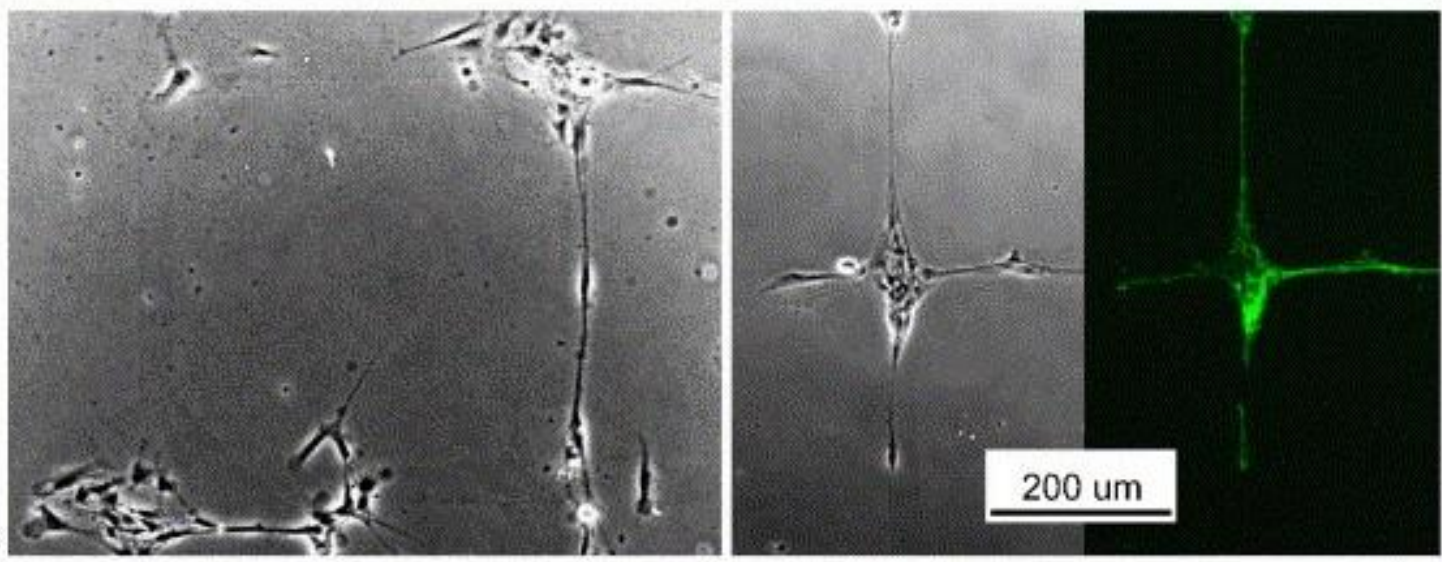

(c)

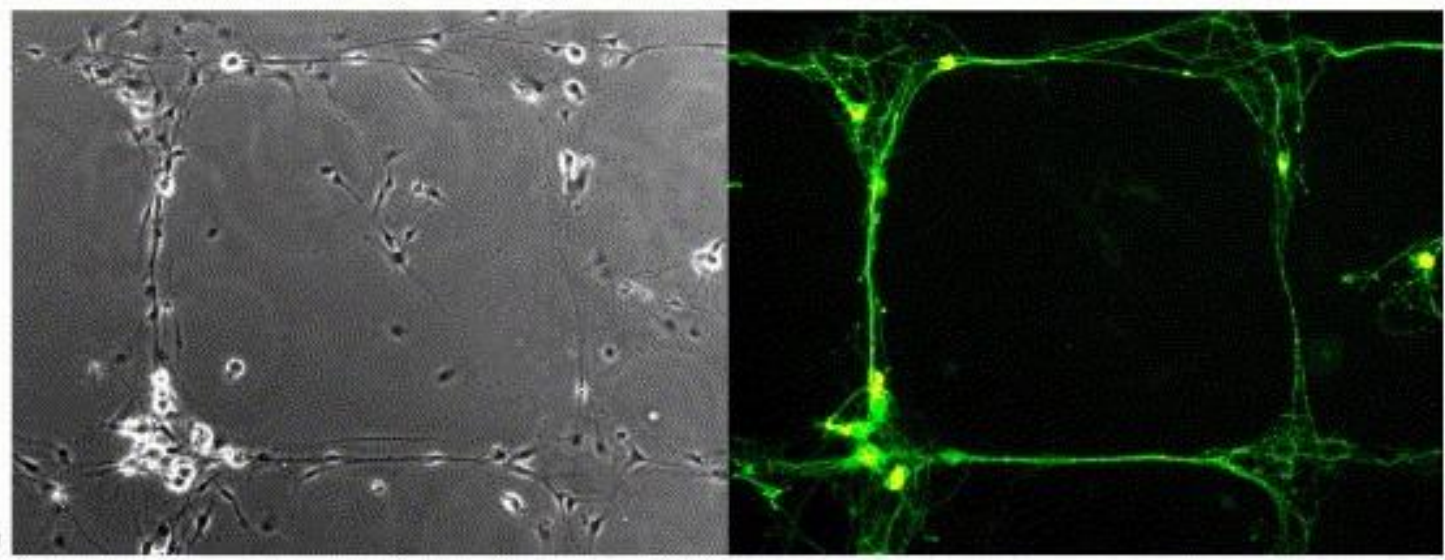

Figure 9. Phase contrast and fluorescent images of DRG adhered to a surface of PPy[pGlu]$\mathrm{X}$ where $\mathrm{X}=$ (a) pLys, (b) Lmn and (c) pLys-Lmn. The cells were fixed at 2 days (a and c) or at 12 days (b) after plating. Neurites stained positive for GAP-43 (green fluorescence). Cell nuclei were labelled with DAPI (blue fluorescence). All images were taken at $10 \times$ magnification and thus, the $200 \mu \mathrm{m}$ scale bar in (b) applies to all images shown ${ }^{[25]}$. 


\section{WILEY-VCH}

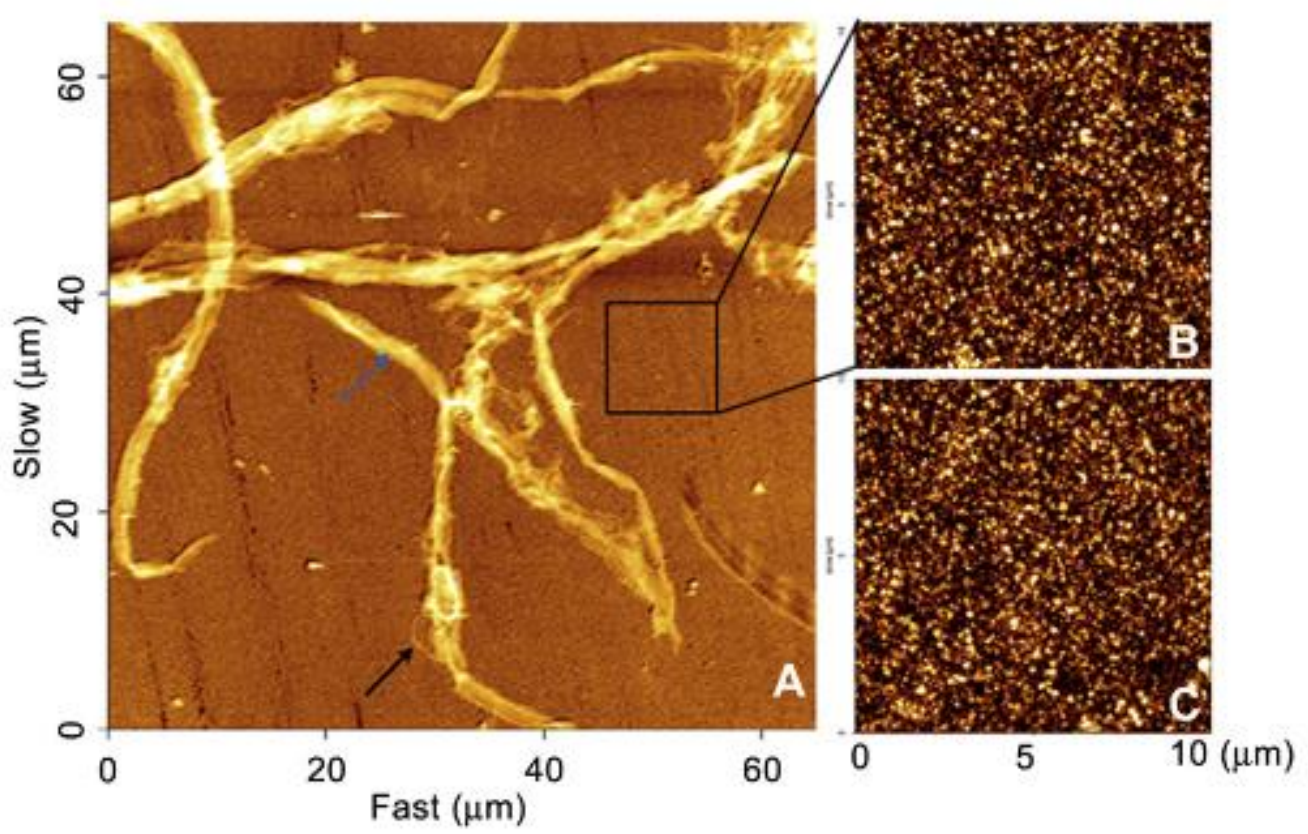

Figure 10. AFM micrographs of PPy/CS/Col film (A), amplified area on PPy/CS/Col film without collagen fibers (B) and pristine PPy/CS film (C) in PBS. Blue arrow-large fibrous structure; Black arrow - smaller individual fibres ${ }^{[76]}$. 


\section{WILEY-VCH}

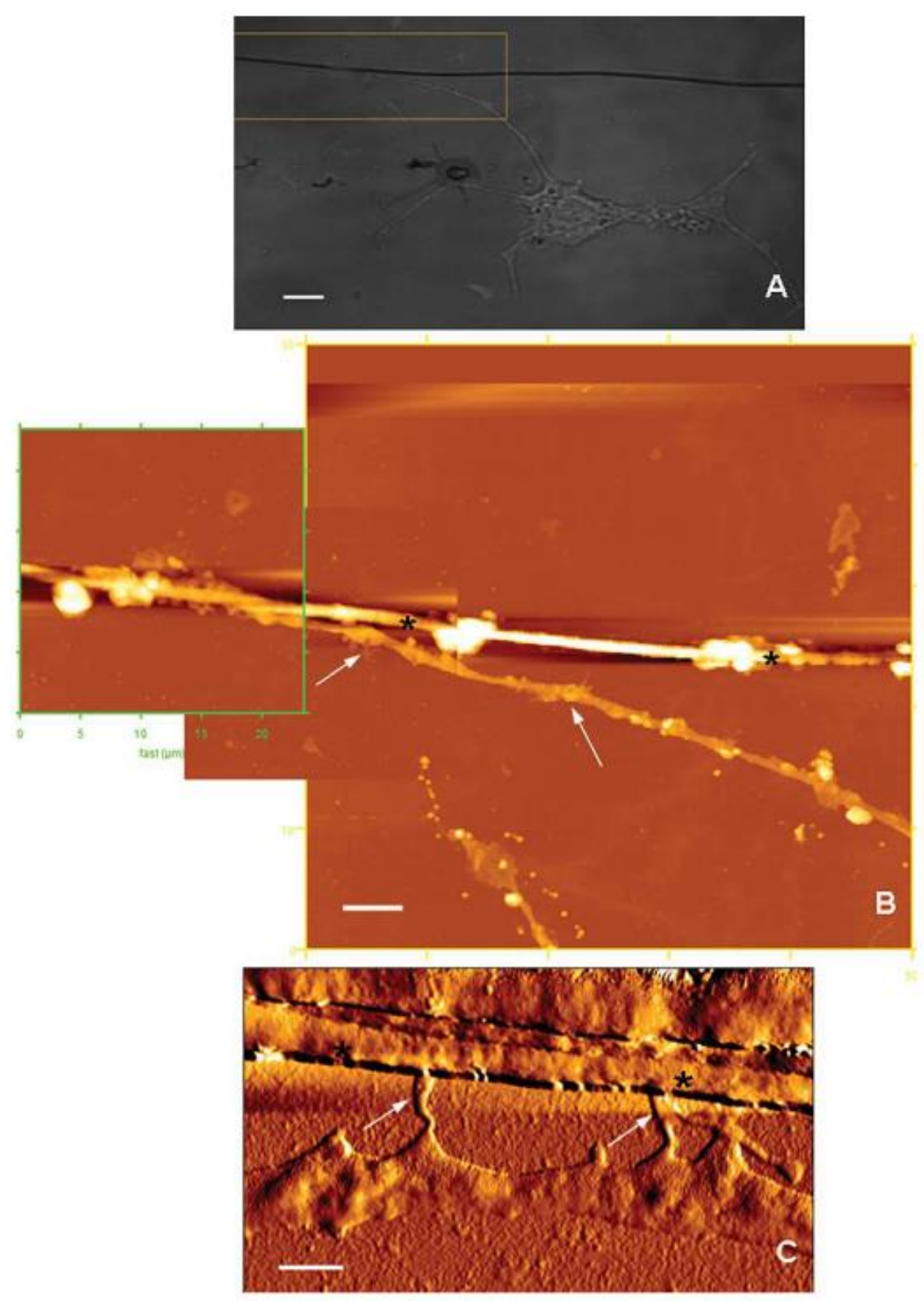

Figure 11. (A) Optical and (B) corresponding AFM images of the boxed region in (A) showing a neurite (arrows) extending along a PPy/SIBS fibre (black asterisks). Scale bar in (A) $=20 \mu \mathrm{m}$. Scale bar in (B) $=5 \mu \mathrm{m}$. (C) High-resolution AFM image showing small finger-like lateral outgrowths (arrows) making contact with a PPy/SIBS fibre (black asterisks). Scale bar in $(C)=1 \mu \mathrm{m}^{[28]}$. 


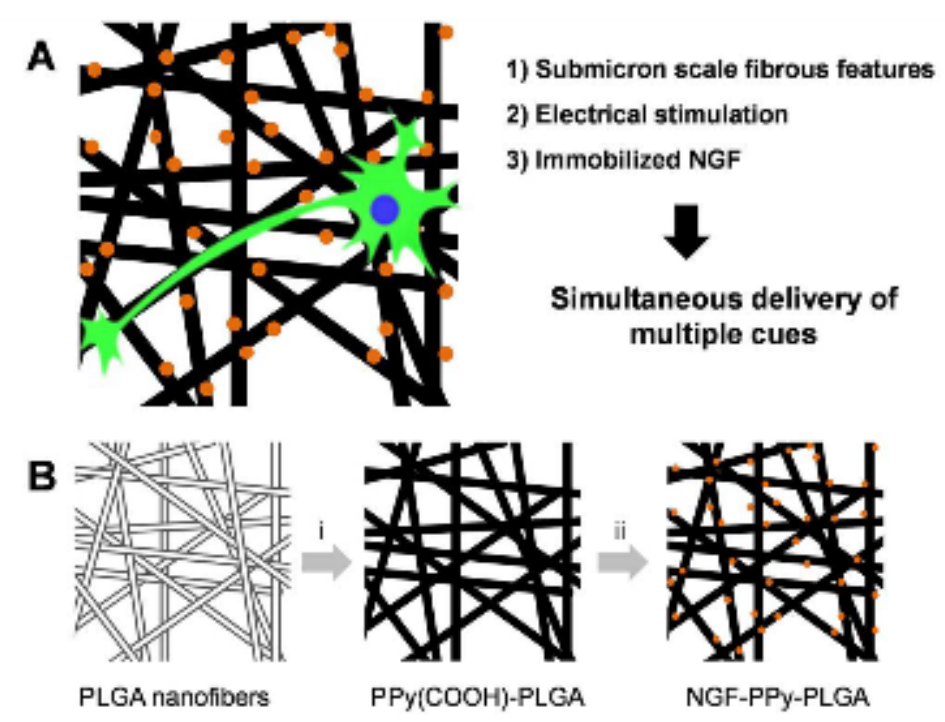

Figure 12. A. NGF/PPy/PLGA provides multiple cues for neurite outgrowth as the scaffolds deliver submicrometer-scale fibrous features, electrical conductivity, and neurotrophic activity. B. Schematic for fabricating NGF immobilized PPy/PLGA fibers (NGF/PPy/PLGA). i) Electrospun PLGA nanofibers were coated with $\mathrm{PPy}$ and $\mathrm{PPy}(\mathrm{COOH})$, producing $\mathrm{PPy}(\mathrm{COOH}) / \mathrm{PLGA}$. ii) NGF (represented as circles) was chemically immobilized onto $\mathrm{PPy}(\mathrm{COOH}) / \mathrm{PLGA}^{[27]}$. 


\section{WILEY-VCH}

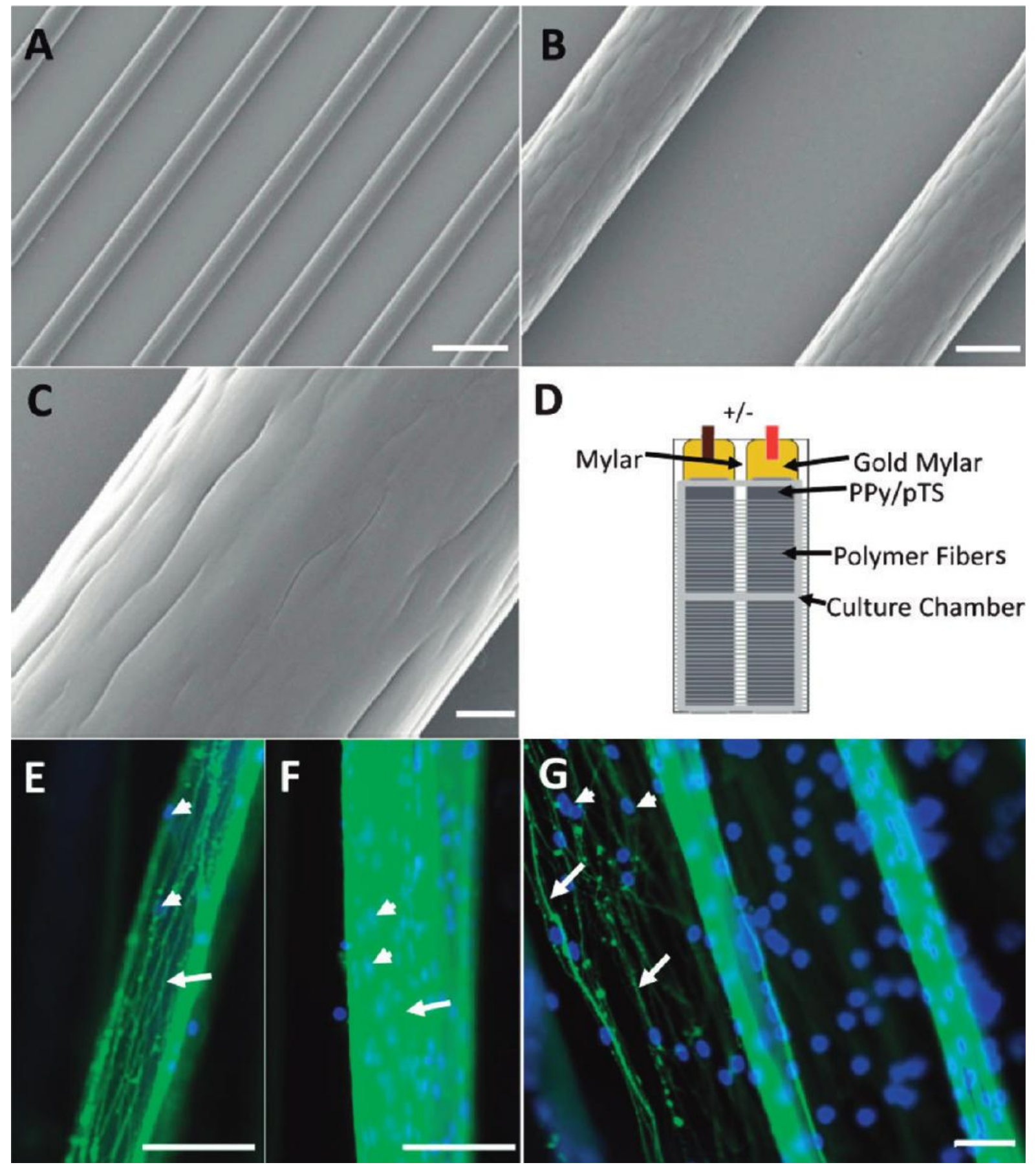

Figure 13. SEM images $(\mathrm{A}-\mathrm{C})$ reveal a relatively smooth PPy surface, in which PLA: PLGA fibers are embedded. Tissue culture chambers were attached to the scaffold surface to facilitate DRG growth and stimulation (D). Axon growth (arrows) and Schwann cell (arrow heads) migration is observed on both the biodegradable fibers ( $\mathrm{E}$ and $\mathrm{F}$ ) and the PPy/pTS surface $(\mathrm{G})$. Fluorescent microscopy images $(\mathrm{E}-\mathrm{G})$ demonstrate that axonal growth and Schwann cell migration follow the path of the embedded polymer fibers on both stimulated and unstimulated scaffolds. Scale bars $=100 \mu \mathrm{m}(\mathrm{A}), 20 \mu \mathrm{m}(\mathrm{B}), 5 \mu \mathrm{m}(\mathrm{C})$, and $50 \mu \mathrm{m}$ (E$\mathrm{G})^{[18]}$. 
(a) Individual strand of ECP

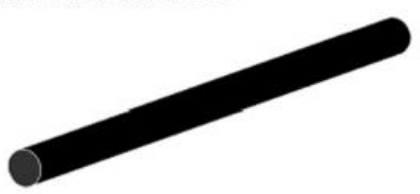

(b) Neuronal adhesion, survival, and neurite outgrowth to permit network formation directly on ECP strand

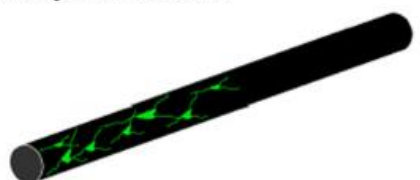

(c) Hydrogel encapsulation to form a protective barrier while maintaining neuronal adhesion on ECP, potentially fostering network stability

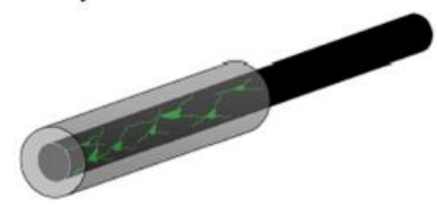

(d) Multiple individual channels may be integrated for complex interface microsystems

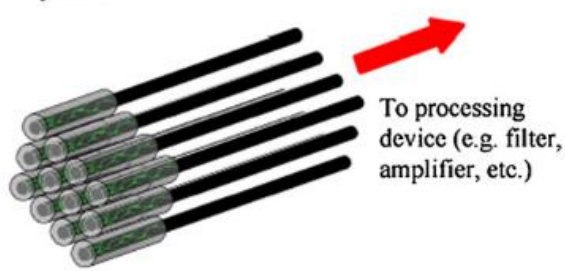

Figure 14. Tissue-engineered neural-electrical relays. Small diameter $(<400 \mu \mathrm{m})$ electrically conducting PA-PP fibers were chosen as the electrical interface due to their mechanical compliance and tailored conductive properties (a). PANi-PP fibers were processed to permit neuronal growth and network formation directly on the fibers (b). Then, these biohybridized neural-conductive fibers were encapsulated with a bio-inert hydrogel to form a protective barrier while potentially stabilizing the network in intimate contact with the PANi-PP (c). A multitude of relays may be used in parallel to create complex interface microsystems, with the alternate end of the PANi-PP fiber projecting to a processing device for signal filtering, amplification and output (d). These 'wet' biohybrid neural interface systems may be used as investigative platforms in vitro or as biohybrid relays in vivo ${ }^{[19]}$. 


\section{WILEY-VCH}
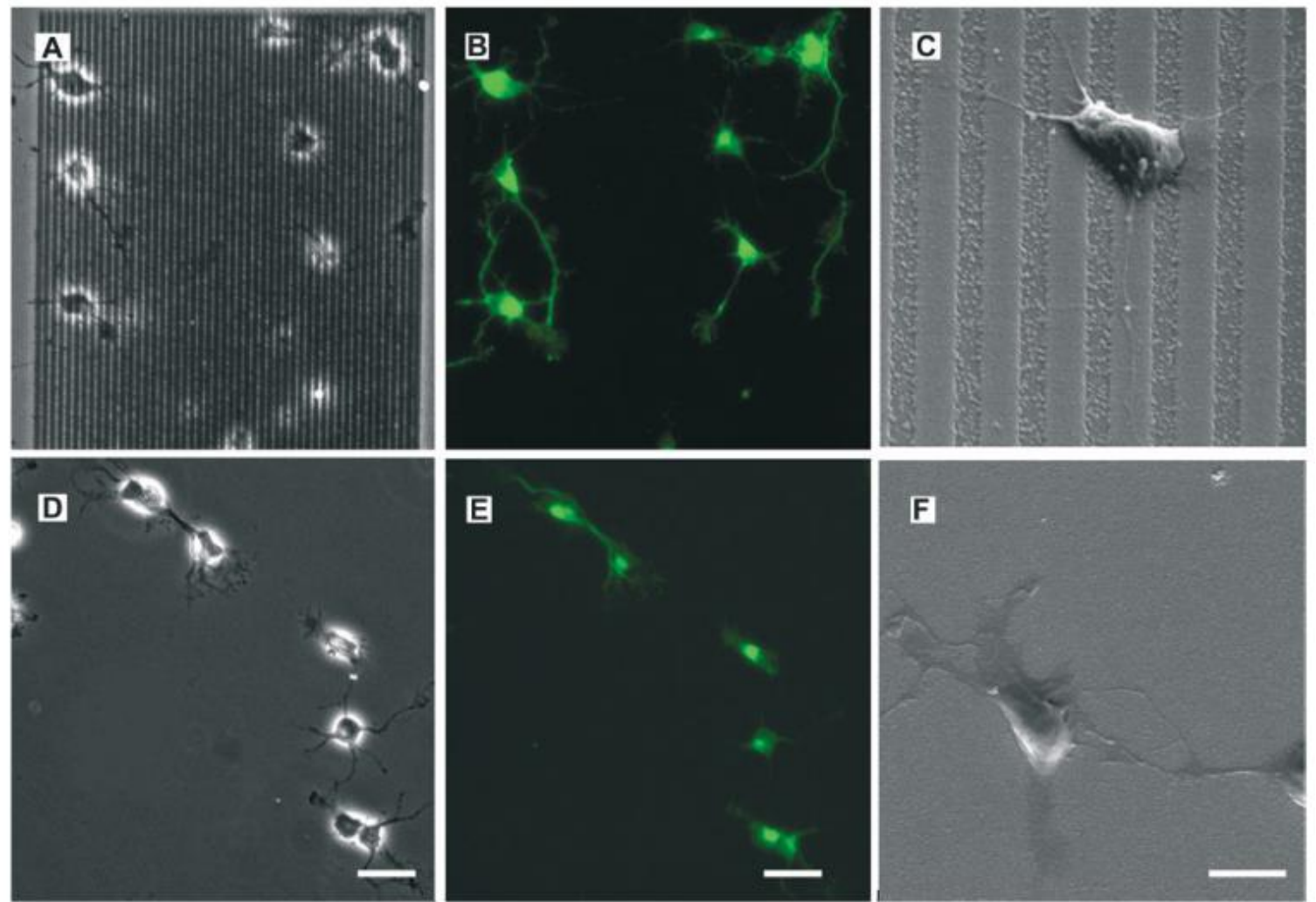

Figure 15. From left to right: phase-contrast, fluorescence, and SEM microscopy images, of hippocampal neurons on PPy. A-C) Cells cultured on $2 \mu \mathrm{m}$ wide and $200 \mu \mathrm{m}$ deep PPymicrochannels; D-F) cells cultured on unmodified PPy. The green labelling (Alexa 488) corresponds to Tau-1 (axonal marker) immunostaining. Cells polarized more readily on microchannels than on unmodified PPy. The scale bar is $20 \mu \mathrm{m}(\mathrm{A}, \mathrm{B}, \mathrm{D}, \mathrm{E})$ and $5 \mu \mathrm{m}(\mathrm{C}, \mathrm{F})^{[20]}$. 


\section{WILEY-VCH}
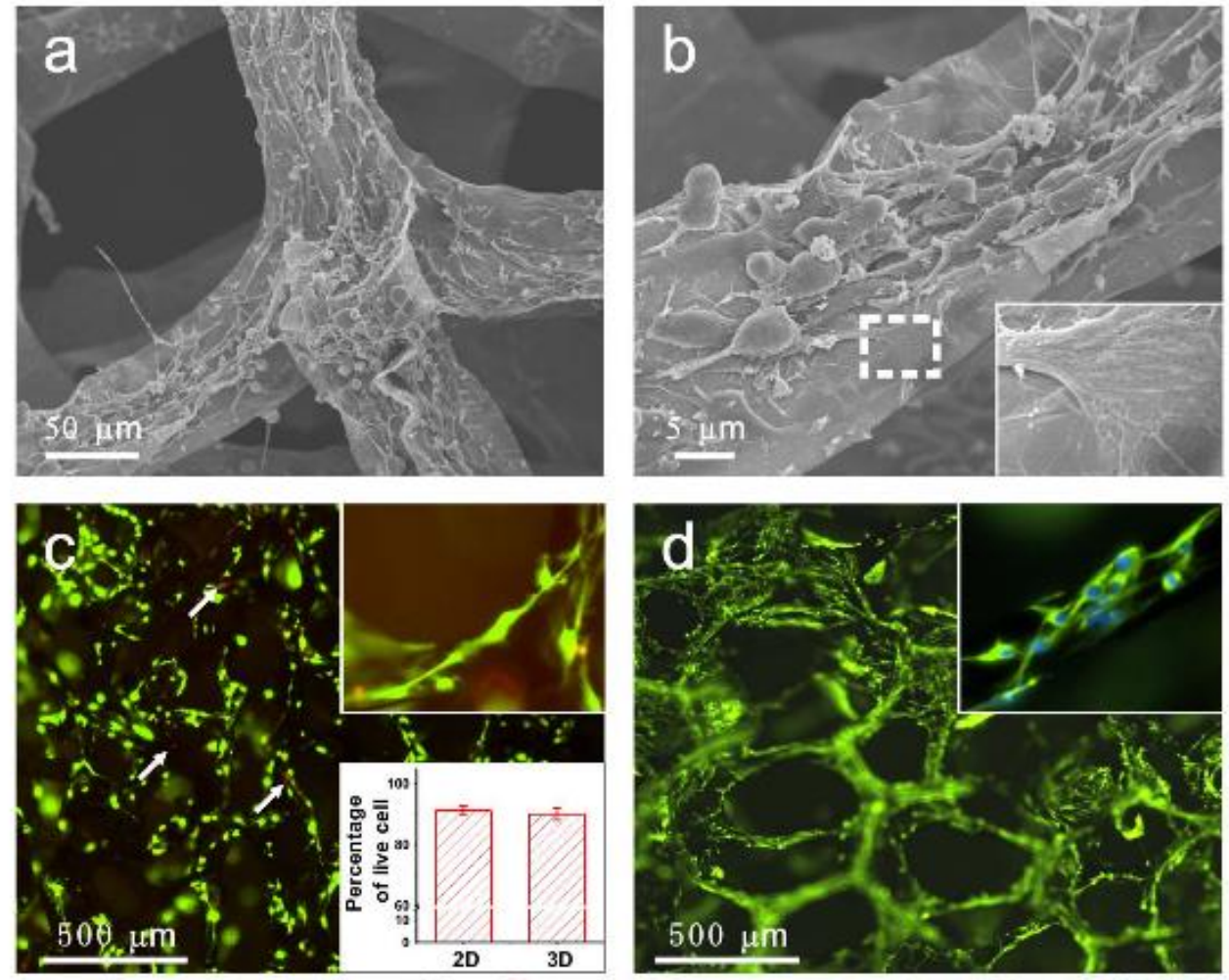

Live/Dead
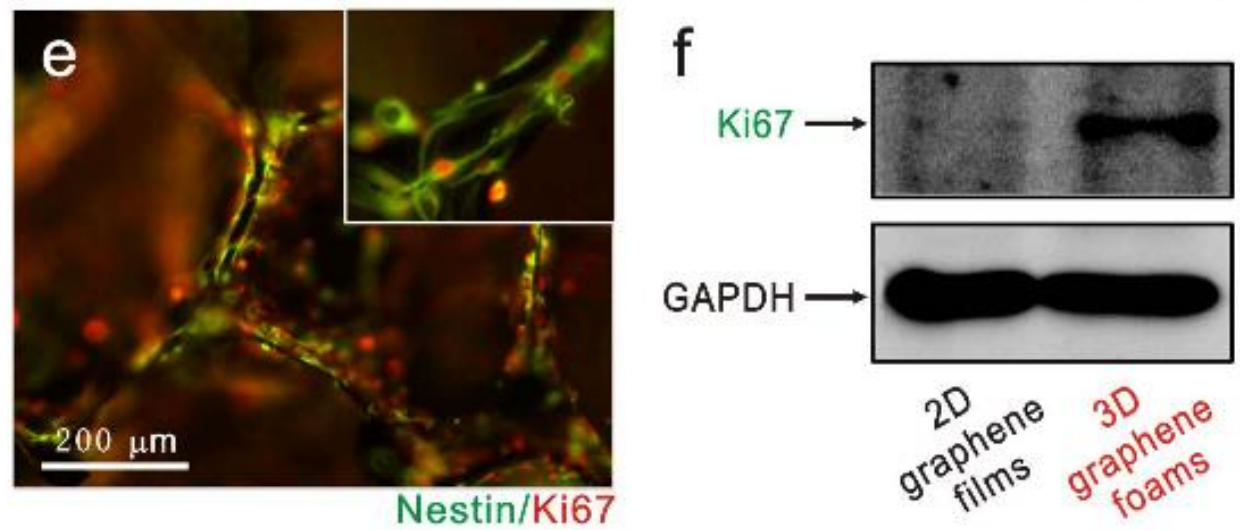

Figure 16. NSCs adhesion and proliferation on 3D-GF scaffold. Low- (a) and high- (b) magnified SEM images of NSCs cultured on 3D-GFs under the proliferation medium. The inset illustrates the interaction between the cell filopodia and 3D-GF surface. (c) Cell viability assay of NSCs on 3D- GFs after 5 days of culture as determined by live/dead assay, live cells are stained green and dead cells are red, white arrow points to dead cell. The lower right inset depicts the percentage of live cell on 2D graphene films and 3D-GFs. (d) Fluorescence images of NSCs proliferated on 3D-GFs for 5 days, immunostaining markers were nestin (green) for neural stem cells and DAPI (blue) for nuclei. (e) NSCs were double-immunostained with antiKi67 (red) and anti-nestin (green) antibodies, Ki67 is a marker for cell proliferation. (f) Western Blot analysis of Ki67 expression on 2D graphene films and 3D-GFs. The Data are presented as mean \pm standard error (s. e. m.), ${ }^{*} \mathrm{p}<0.05, * * \mathrm{p}<0.01^{[106]}$. 


\section{WILEY-VCH}

Table 1. Most widely studied materials for nerve conduit with related properties and selected studies where they were used ${ }^{[44]}$.

\begin{tabular}{|c|c|c|}
\hline NC polymers & Characteristics & References \\
\hline Silicone:poly(dimethylsiloxane) & $\begin{array}{l}\text { Highly elastomeric polymer, non-biodegradable, bioinert, } \\
\text { impermeable, hydrophobic }\end{array}$ & {$[45,48]$} \\
\hline PGA: poly(glycolide) & $\begin{array}{l}\text { Aliphatic polyester, biodegradable by hydrolysis, Commercial NC } \\
\text { approved by FDA }\end{array}$ & {$[34]$} \\
\hline PHB: poly(3-hydroxybutyrate) & Aliphatic polyester, biodegradable by hydrolysis & [49] \\
\hline PLA: poly(L-lactide) acid & $\begin{array}{l}\text { Aliphatic polyester, very slowly biodegradable } \\
\text { by hydrolysis }\end{array}$ & {$[35]$} \\
\hline PLGA:poly(DL-lactide)co-glycolide & $\begin{array}{l}\text { Aliphatic polyester, slowly biodegradable } \\
\text { by hydrolysis }\end{array}$ & {$[29,50]$} \\
\hline Chitosan:b-(1-4)-linked D-glucosamine & Polysaccharide, enzymatically degradable & {$[50]$} \\
\hline $\begin{array}{l}\text { PHEMA-MMA:poly(2-hydroxyethyl } \\
\text { methacrylate-co-methyl methacrylate) }\end{array}$ & $\begin{array}{l}\text { Hydrogel-forming polymer, nonbiodegradable, } \\
\text { stiffness in the range of nerve tissue }\end{array}$ & {$[51]$} \\
\hline Polyester urethane & Elastomeric polymer, biodegradable & {$[52]$} \\
\hline
\end{tabular}

Table 2. Summary of advantages and disadvantages of biocompatible polymer scaffolds.

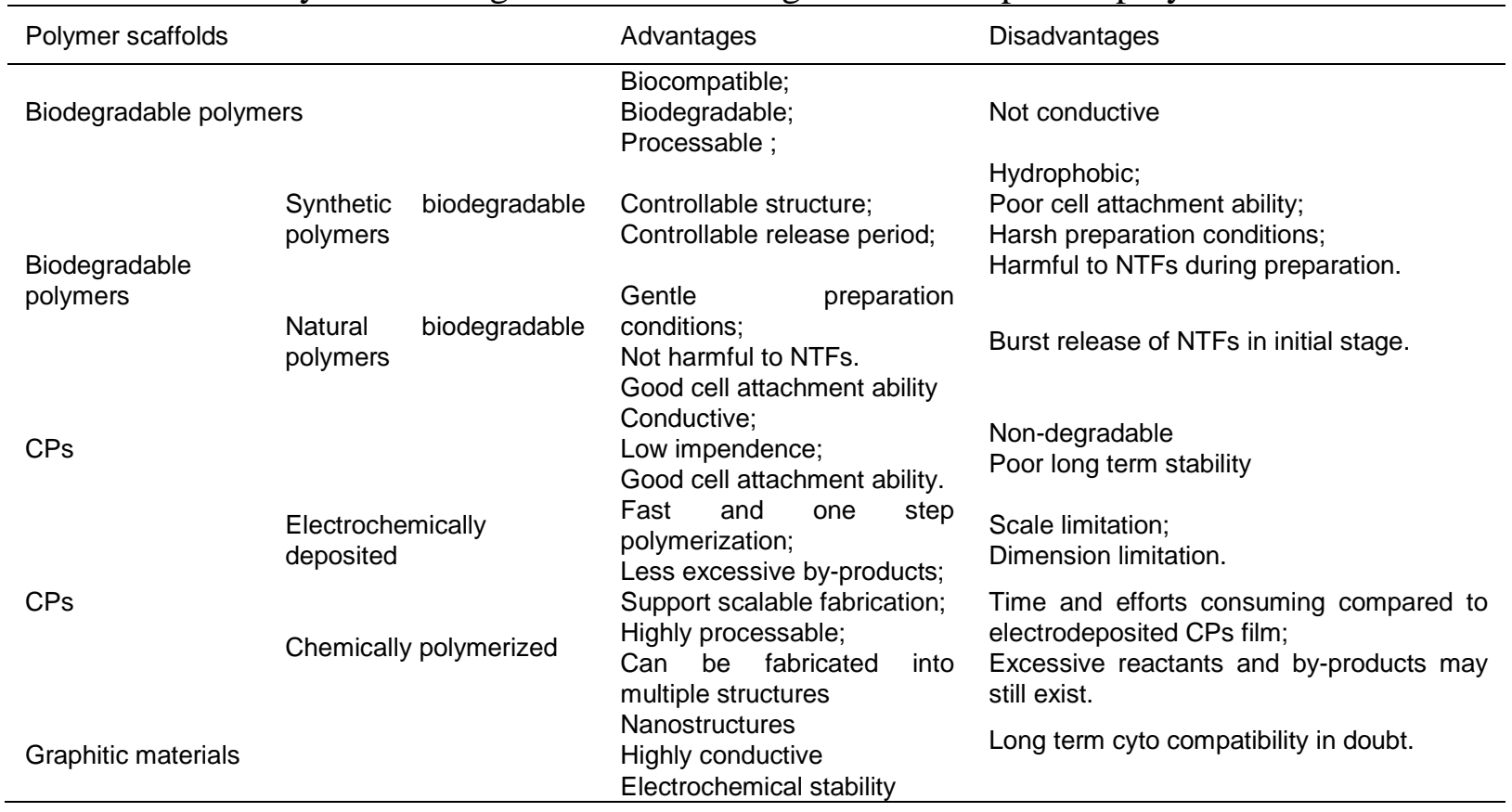

Table 3. Criteria for ideal biocompatible polymer scaffolds.

\begin{tabular}{|c|c|}
\hline Properties & Criteria \\
\hline Biocompatibility & Compatible with neuron cells and in vivo environment \\
\hline Biodegradability & $\begin{array}{l}\text { Ability to decompose in both in vitro and in vivo environments } \\
\text { Decomposition products not harmful } \\
\text { Stability in cell culture environment: }\end{array}$ \\
\hline Physical Interface & $\begin{array}{l}\text { Ability for nanoscale and microscale fabrication to generate topographical stimulation; } \\
\text { Low hardness. } \\
\text { High conductivity; }\end{array}$ \\
\hline Electrical Interface & $\begin{array}{l}\text { Low impendence; } \\
\text { Electrochemical stability; } \\
\text { Good cell attachment and guidance ability; }\end{array}$ \\
\hline Biological Interface & $\begin{array}{l}\text { Ability to deliver NTFs; } \\
\text { Ability to promote cell proliferation and neurite outgrowth. }\end{array}$ \\
\hline
\end{tabular}




\section{WILEY-VCH}

Author Biographies

Dr. Bo Weng

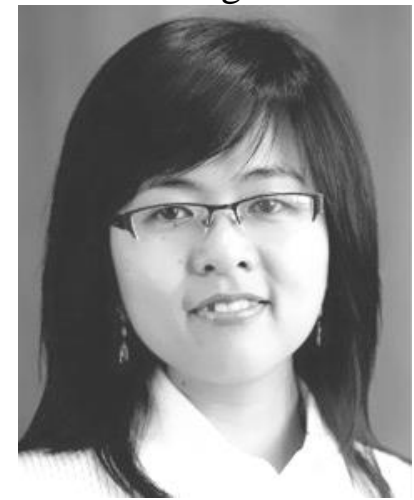

Bo Weng is a lecturer in Southwest University, China. She obtained her Ph.D degree in Chemistry from the University of Wollongong, Australia in 2012. After that, she worked as a research fellow in the University of Wollongong and University of Sydney for one and a half years. Her research interests are mainly focused on the nano- and micro-fabrication of conducting polymers and their applications in tissue engineering and biosensing.

Associate Professor Jun Chen

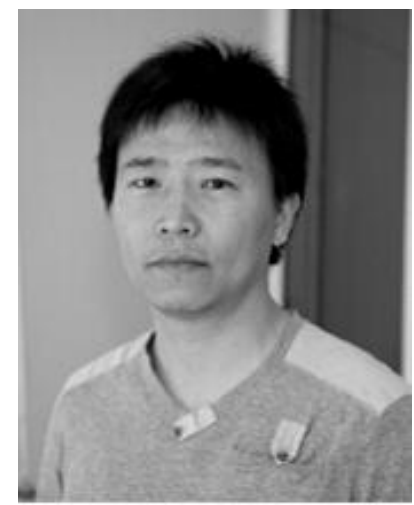

Jun Chen is an associate professor in the University of Wollongong. He obtained his $\mathrm{PhD}$ degree in 2003 from the University of Wollongong with a joint scholarship between UOW and CSIRO. He work as a research fellow in the University of Wollongong between 2003 and 2013 and was appointed as associate professor in May 2013. His reseach interests are mainly focussed on nanomaterials (such as nanocarbon materials, polymer composites, and active inorganic nanoparticles), electrocatalysts, and sustainable energy devices, including both energy storage (supercapacitor, and Li-ion battery) and energy conversion (fuel cell and water splitting) devices. 


\section{WILEY-VCH}

Professor Changming Li

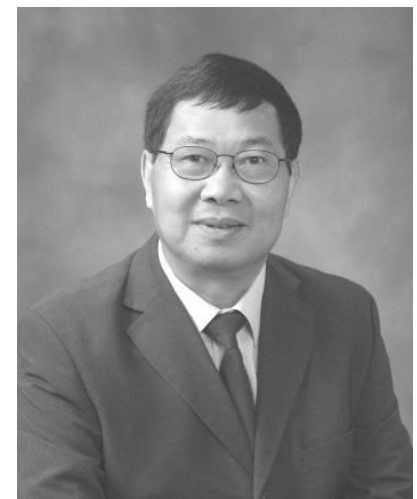

Changming $\mathrm{Li}$ is the director of Institute for Clean Energy and Advanced Materials, Southwest University, China. He received his PhD degrees from Wuhan University in 1986, followed by postdoctoral research under Prof. Larry F. Faulkner in the University of Illinois at Urbana-Champaign. He was appointed as head of Bioengineering Division and Director for Advanced Bionanosystems in NTU in 2008 and moved to Southwest University in 2012. Professor Li's research interests cover biosensor/lab-on-a-chip, nanomaterials and biotechnology, bio/nanoelectronics and green energies (solar, fuel cells, lithium batteries and supercapacitors). 


\section{WILEY-VCH}

This paper reviews the studies in the bio-interface of polymer based materials for neuroregeneration, discussing various interfacial stimulation methods (interfacial NTFs delivery, surface guidance, electrical stimulation and molecules decoration) that biopolymers can provide to lesion neural cells/tissues, and proposes the criteria and perspective of biointerface of polymer for neuroregeneration for future development.

Keywords: Neuroregeneration; Bio-interface; Conducting Polymers; Biomaterials

Bo Weng*, Jianglin Diao, Qun Xu, Yuqing Liu, Changming Li, Ailing Ding and Jun Chen*

Title Bio-interface of Conducting Polymer-based Biomaterials for Neuroregeneration

ToC figure ((Please choose one size: $55 \mathrm{~mm}$ broad $\times 50 \mathrm{~mm}$ high or $110 \mathrm{~mm}$ broad $\times 20 \mathrm{~mm}$ high. Please do not use any other dimensions))

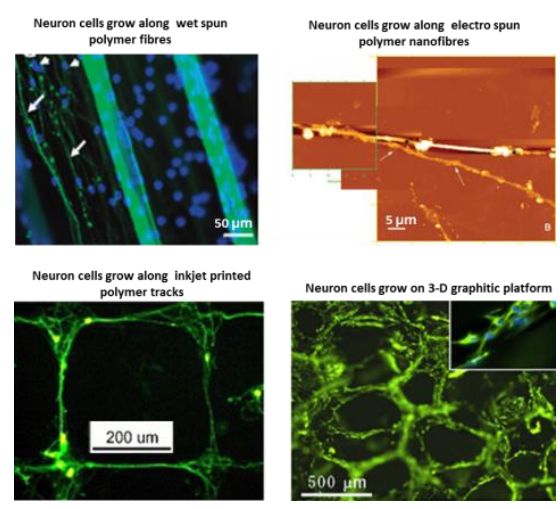

